Van Dijke, M., Wildschut, T., Leunissen, J., \& Sedikides, C. (2015). Nostalgia buffers the negative impact of low procedural injustice on cooperation. Organizational Behavior and Human Decision Processes, 127, 15-29. doi: 10.1016/j.obhdp.2014.11.005

RUNNING HEAD: NOSTALGIA AND JUSTICE

Nostalgia Buffers the Negative Impact of Low Procedural Justice on Cooperation

Marius van Dijke

Rotterdam School of Management

Tim Wildschut

University of Southampton

Joost M. Leunissen

Rotterdam School of Management and University of Southampton

Constantine Sedikides

University of Southampton 


\begin{abstract}
This research integrates the discrete emotion of nostalgia (a sentimental longing for the past) with relational models of procedural justice. An organizational survey and four experiments demonstrated that nostalgia buffers (i.e., weakens) the deleterious impact of low (compared to high) procedural justice on organizational citizenship behavior (OCB) and cooperation with authorities. Low procedural justice undermined social connectedness with authorities, and nostalgia's buffering role derived from its capacity to block the pathway from this reduced social connectedness to decreased OCB and cooperation. This research presents the first evidence that a discrete emotion—nostalgia — functions as a resource that aids individuals in coping with low procedural justice. Nostalgia thus facilitates cooperation even with authorities and organizations that display low procedural justice.
\end{abstract}

Keywords: procedural justice, nostalgia, buffer, organizational citizenship, cooperation 
It is essential for the proper functioning of organizations that individuals focus on the welfare of the collective and its members rather than indulging their own interests (De Cremer \& Tyler, 2005; Podsakoff, Whiting, Podsakoff, \& Blume, 2009). Yet, the display of such cooperative behavior is undermined when members find that their social connectedness to the organization and its authorities (e.g., supervisors, managers, leaders) is compromised (Thau, Aquino, \& Poortvliet, 2007). Members may base their sense of connectedness on the fairness of decision making or outcome allocation procedures (i.e., procedural justice; Sedikides, Hart, \& De Cremer, 2008; Van Prooijen, Van den Bos, \& Wilke, 2002). According to relational justice models, high procedural justice (i.e., decision making procedures being perceived as fair) contributes to a sense of social connection with the collective and its authorities, whereas low procedural justice (i.e., decision making procedures being perceived as unfair) engenders a sense of exclusion. Hence, low procedural justice damages cooperation (Cohen-Charash \& Spector, 2001; Colquitt, Conlon, Wesson, Porter, \& Yee, 2001), because it dents employees' social connectedness (De Cremer \& Tyler, 2005; Tyler \& Blader, 2003).

Compromised social connectedness (e.g., as resulting from low procedural justice) is likely distressing (Baumeister, 2012; Leary, 2005). Yet, research is surprisingly silent about how organization members cope with this situation. Members may cope directly with social connectedness deficiencies by forming or repairing relationships with suitable interaction partners or by retaliating (Williams, Forgas, \& von Hippel, 2005). Indeed, low procedural justice renders individuals more likely to strike back, passively withdraw, or exit from the organization (Ambrose, Seabright, \& Schminke, 2002; Colquitt et al., 2013). However, such actions may culminate in undesirable status consequences (e.g., reduced privileges associated with organizational membership or seniority), reputation, or tangible outcomes (e.g., salary, promotion). Thus, organization members may often need to resort to indirect compensatory mechanisms involving mental representations of social bonds as a source of social connectedness in order to cope with the aversive experience of low procedural justice (Gardner, Pickett, \& Knowles, 2005; Leary, 2005). We propose that individuals can cope with social connectedness deficiencies that accompany low procedural justice by recruiting 
nostalgic recollections as an indirect compensatory strategy.

A burgeoning literature, which we review below, indicates that a core function of nostalgia is to serve as a reservoir of social connectedness (Sedikides et al., 2015; Sedikides, Wildschut, Routledge, Arndt, \& Zhou, 2009). By communicating that one's connectedness to the organization or its authorities is compromised, low procedural justice constitutes a psychological threat. In light of nostalgia's versatility in bringing to life meaningful connections from one's past (even connections far removed from organizational reality), we expect that it helps individuals to cope with reduced connectedness to a specific collective or authority. This implies that nostalgia facilitates keeping up high cooperation in the face of low procedural justice. Figure 1 depicts our proposed model.

We aim to make two contributions to the literature. First, compromised connectedness (e.g., as resulting from low procedural justice) is a ubiquitous aspect of social and organizational life (Baumeister, 2012; Johnson, Lanaj, \& Barnes, 2014). Yet, current theory does not explain how individuals cope with low procedural justice while simultaneously maintaining high levels of cooperation. Building on the need to belong literature (Baumeister, 2012; Baumeister \& Leary, 1995), we argue that nostalgia may be recruited as an indirect strategy to cope with the compromised connectedness that stems from low procedural justice, allowing individuals to sustain cooperation. Second, emotions are important in shaping responses to procedural justice; yet, their exact role is poorly understood (Colquitt et al., 2013; Cropanzano, Stein, \& Nadisic, 2011). We integrate the role of a discrete emotion nostalgia - with relational models of procedural justice (De Cremer \& Tyler, 2005; Tyler \& Blader, 2003). In so doing, our investigation begins to bridge the gap between the emotion and justice literatures.

\section{Procedural Justice}

Procedural justice is shaped by several factors. For example, procedures are perceived as fairer when they are applied consistently over time and across organizational members (Van den Bos, Vermunt, \& Wilke, 1996), when they are applied accurately and are not motivated by authorities' self-interest (De Cremer, 2004), and when they allow members to 
voice their opinion (Thibaut \& Walker, 1975). Members find procedural justice important for its own sake (i.e., as a matter of moral principle; Cropanzano, Byrne, Bobocel, \& Rupp, 2001), but also because it addresses instrumental needs by helping to promote long term personal goals (while low justice jeopardizes such goals; Thibaut \& Walker, 1975).

In addition, relational justice models emphasize that procedures address relational needs (Lind \& Tyler, 1988; Tyler \& Lind, 1992). This is a key reason why members are attentive to information about their connectedness to the collective (De Cremer \& Blader, 2006; Tyler \& Smith, 1999). Fairly enacted procedures signal that one is included in and valued by the collective (Smith, Tyler, Huo, Ortiz, \& Lind, 1998; Van Dijke \& De Cremer, 2008). This increases motivation to cooperate for the purpose of benefitting the collective and its representative authorities (Van Dijke et al., in press). Indeed, procedural justice promotes cooperation in experimental (De Cremer, Van Dijke, \& Mayer, 2010) and field (Blader \& Tyler, 2009) settings.

A well-documented outcome of procedural justice is organizational citizenship behavior (OCB; Cohen-Charash \& Spector, 2001; Colquitt et al., 2001). OCB is a key index of employee cooperation, because it describes various types of discretionary or extrarole behaviors that contribute to effective organizational functioning but that are not explicitly required (Organ, 1988). OCB includes behaviors as varied as voluntarily helping one's supervisors or coworkers and speaking up to improve the way in which work is organized. Taken together, procedural justice promotes connectedness to the collective, which facilitates various cooperative behaviors (Blader \& Tyler, 2009; Van Dijke, De Cremer, Mayer, \& Van Quaquebeke, 2012).

\section{Nostalgia}

Nostalgia has been historically regarded as a brain malfunction, psychiatric disorder, or variant of depression (Batcho, 2013; Sedikides, Wildschut, \& Baden, 2004). Recent evidence indicates that this uncomplimentary view is undeserved. Hepper, Ritchie, Sedikides, and Wildschut (2012) found that laypersons conceptualize nostalgia as a predominantly positive, social, and past-oriented emotion. In nostalgic reverie, one remembers an event from 
one's past — typically a fond, personally meaningful episode pertaining to one's childhood or a close relationship. One often views the recollection through rose-tinted glasses, misses that time or person, and may even long to return to the past. As a result, one typically feels sentimental, most often happy but with a tinge of longing. These lay conceptions of nostalgia are shared across cultures (Hepper et al., 2014) and dovetail with formal dictionary definitions; The New Oxford Dictionary of English (1998) defines nostalgia as "a sentimental longing or wistful affection for the past" (p. 1266). Nostalgia occurs relatively frequently (e.g., about 3 times a week in a sample of university students; Wildschut, Sedikides, Arndt, \& Routledge, 2006) and is experienced by almost everyone (Boym, 2001; Routledge et al., 2011; Wildschut, Sedikides, Routledge, Arndt, \& Cordaro, 2010). Nostalgia has a powerful, positive impact on how individuals perceive themselves, how meaningful they perceive life to be, how optimistic they see their future, and how connected they feel to others (Cheung et al., 2013; Routledge, Wildschut, Sedikides, Juhl, \& Arndt, 2012).

Indeed, a core psychological function of nostalgia is the provision of social connectedness. On the basis of their analysis of the nostalgia construct, Hepper et al. (2012) concluded that close others (friends, family, partners, and even pets) along with interpersonal elements or concepts (belonging, cuddles, tender moments, warmth, love) are perceived as centrally defining features of nostalgia. Content analytic and survey studies have established that close others and momentous life events involving close others comprise the bulk of nostalgic referents (Abeyta, Routledge, Sedikides, \& Wildschut, in press; Holak \& Havlena, 1992; Wildschut et al., 2006). In addition, when experimentally induced, nostalgia springs sociality. It nurtures sentiments of being protected and loved, reduces attachment anxiety and attachment avoidance, and engenders perceptions of social support that counteract loneliness. Nostalgia also raises estimates of the number of friends one has, augments volunteering intentions and actual charity donations, and increases helping behavior (Stephan et al., 2014; Zhou, Sedikides, Wildschut, \& Gao, 2008; Zhou, Wildschut, Sedikides, Shi, \& Feng, 2012). In all, the literature underpins the idea that, by rendering accessible mental representations of close relationships from the past, nostalgia strengthens social connectedness in the present 
(Wildschut et al., 2006, 2010). For example, nostalgic recollections of time spent with a dear

friend may fortify one's sense of being valued by others, even when current events (e.g., falling victim to low procedural justice) question this.

\section{Nostalgia as a Buffer Against Low Procedural Justice}

Low (vs. high) procedural justice communicates to members that they are not valued by or included in the organization, and this signal can diminish cooperation (De Cremer \& Blader, 2006). Communicating information about belongingness to a collective or authority has implications for a potent human motivation, the need to belong (Baumeister 2012). Individuals routinely assess how well they are connected with others and what their general outlook is for belongingness in future relationships. In doing this, individuals respond to "actual cues in the immediate environment but also to remembered, anticipated, and imagined stimuli in the person's own mind" (Leary, 2005, p. 89-90, italics added). This preoccupation with different types of belongingness information implies that the relevant need may be satisfied by various means (Baumeister, 2012) and that, when the need is momentarily satisfied, specific relational experiences of weakened connectedness may be less damaging to well-being and behavior (Gardner et al., 2005). Consistent with this possibility, the often observed effect of social exclusion on aggression is attenuated when a person who is unrelated to the exclusion situation behaves in a friendly manner toward the excluded participant or when participants briefly recall a favorite family member (Twenge et al., 2007).

These arguments support the notion that individuals can cope with deficiencies in social connectedness to a specific collective or authority (e.g., as resulting from low procedural justice) by using indirect compensatory mechanisms that rely on mental representations of social bonds as a source of social connectedness (Gardner et al., 2005). Nostalgia may be seen as a momentary state which reminds individuals that they are capable of meaningful connections with others. Although nostalgic recollections are usually about something in the distant past and unrelated to current experiences of threatened belongingness, they may momentarily satisfy the need to belong, thus granting individuals the fortitude to cope with weakened connectedness to any specific authority (as a result of low procedural justice), at 
least for the duration of the nostalgic experience. This should make compromised connectedness to an authority or organization less threatening and less requisitive of a response (such as reduced cooperation; Aquino \& Douglas, 2003). Hence, low procedural justice will undermine cooperation (as the literature indicates) only when nostalgia is low. When nostalgia is high, individuals will be able to absorb the negative psychological impact of low procedural justice and manifest a relatively high level of cooperation. This argument culminates in Hypothesis 1:

Low (vs. high) procedural justice leads to decreased cooperation, but this effect is buffered by high (vs. low) nostalgia.

As an explicit test of our argument, we examine social connectedness to the authority as a mediating mechanism. Relational justice models suggest that procedural justice is an aversive experience not because people intrinsically dislike low procedural justice (e.g., not receiving voice), but because it communicates that one's connectedness with an authority or a social collective is compromised (De Cremer \& Tyler, 2005; Tyler \& Blader, 2003). Nostalgia, as a repository of social connectedness, is not expected to moderate the path from lowered procedural justice to lowered perceptions of connectedness to an authority or collective. Instead, nostalgia should aid individuals in coping with the experience of low connectedness to an authority and, by so doing, maintain a high level of cooperation. If nostalgia aids individuals in coping specifically with the perception of lowered connectedness to the authority, it should obstruct the path from compromised connectedness to lowered cooperation. Our argument is summarized in Figure 1 and culminates in Hypothesis 2:

Low (vs. high) procedural justice leads to decreased cooperation via the mediating mechanism of weakened connectedness with the authority. However, high (vs. low) nostalgia buffers the relation between weakened connectedness with the authority and decreased cooperation, thereby maintaining cooperation levels.

\section{Overview}

We tested our hypotheses in five studies. Study 1 is a survey, situated in a work context. We operationalized employee cooperation as OCB. We followed the convention in the 
literature and tested whether employees' perceptions of low (compared to high) procedural justice in their organization (i.e., not referring to a specific target or event) are related to reduced OCB (Cohen-Charash \& Spector, 2001; Colquitt et al., 2001, 2013). Given our broad operationalizations of procedural justice and cooperation, we likewise operationalized nostalgia as individual differences in nostalgia proneness. Persons who are high (vs. low) in nostalgia proneness cope effectively with adversity (Routledge, Arndt, Sedikides, \& Wildschut, 2008; Seehusen et al., 2013), because they recruit nostalgia in relevant situations (Barrett et al., 2010; Juhl, Routledge, Arndt, Sedikides, \& Wildschut, 2010).

Study 2 a laboratory experiment, addressed the limitations inherent to Study 1's survey design. We implemented validated experimental manipulations of nostalgia and procedural justice. Consistent with prior laboratory experiments, we operationalized cooperation as selfreported intentions to cooperate with the enacting authority (De Cremer \& Sedikides, 2005; De Cremer \& Van Knippenberg, 2002; De Cremer, van Dijke, \& Mayer, 2010).

In Studies 3-5, all experimental, we expanded upon the findings from Studies 1-2. We introduced additional behavioral operationalizations of cooperation and yet another operationalization of procedural justice. Furthermore, we examined the key question of how nostalgia buffers the adverse effect of low procedural justice on cooperation. We proposed that nostalgia buffers the negative impact of low (compared to high) procedural justice on cooperation by blocking the path from weakened connectedness to the authority to reduced cooperation (Figure 1). We tested this moderated mediation model. In Study 5, we included the two variables, instrumentality and deontic anger, that purportedly mediate the effect of procedural justice on cooperation (Cropanzano et al., 2001). We would be confident in our claim that nostalgia buffers the negative impact of low (compared to high) procedural justice due to its serving as a repository of social connectedness, if nostalgia blocked the path from reduced social connectedness to lowered cooperation, and not the paths from these two putative mediators to lowered cooperation.

\section{Study 1}

\section{Method}


Participants. We recruited participants via MTurk and paid them \$2.00. We introduced the study as being about "personal and work experiences." Inclusion criteria stated that participants be employed in an organization and have a supervisor (i.e., not be selfemployed). One hundred and thirty participants (of $152 ; 86 \%$ ) met the inclusion criteria (76 men, 54 women; $M_{\text {age }}=32.11, S D_{\text {age }}=10.16$ ). On average, participants had worked in their current organization for 4.94 years $(S D=3.99$; referred to as organization tenure). Twelve percent of participants had completed secondary education only, $14 \%$ subsequent vocational training, 54\% a Bachelor's degree, 20\% a Master's degree, and 1\% a Doctoral degree (referred to as educational level; 1 = high school, 2 = vocational training, 3 =Bachelor's degree, 4 = Master's degree, $5=$ Doctoral degree .

Procedure and materials. Participants responded to materials online. We assessed procedural justice with a 7-item scale developed and validated by Colquitt (2001). Sample items (preceded by the stem "The following questions are about the procedures that are used to arrive at outcomes that you value, such as your salary or promotion opportunities") are: "Have you been able to express your views and feelings during those procedures?", "Have these procedures been applied consistently?" $(1=$ to a small extent, $5=$ to a large extent $)$. We averaged responses to create a procedural justice index $(\alpha=.86, M=3.39, S D=0.78)$.

We measured nostalgia proneness with the 7-item Southampton Nostalgia Scale (Barrett et al., 2010; Routledge et al., 2008). Sample items are: "How often do you experience nostalgia," "How valuable is nostalgia for you?" We averaged responses into a nostalgia proneness scale $(\alpha=.92, M=4.46, S D=1.29)$.

We measured cooperative behavior at work with a 24-item OCB scale (Podsakoff, MacKenzie, Moorman, \& Fetter, 1990). In line with meta-analytic evidence that employees provide more valid ratings of their OCB than supervisors or colleagues do (Carpenter, Berry, \& Houston, 2014), we had participants indicate their OCB. Sample items (preceded by the stem "To what extent do the following statements describe you at work?") are: “Attends meetings that are not mandatory, but are considered important," "Willingly helps others who have work related problems" $(1=$ not at all, $7=$ very $m u c h)$. We formed an OCB index by 
averaging responses $(\alpha=.89, M=3.84, S D=0.48)$.

\section{Results}

We present correlations between the study variables in Table 1 . We tested the buffering role of nostalgia proneness with an ordinary least squares (OLS) regression analysis in which OCB was the criterion variable. As predictor variables, we included the procedural justice index, the nostalgia proneness index, and the Nostalgia Proneness $\times$ Procedural Justice interaction. (We mean-centered nostalgia proneness and procedural justice before calculating the interaction term.)

OCB was not significantly predicted by procedural justice, $\beta=.09, t(126)=1.03, p=.30$, $f^{2}=.01$, or nostalgia proneness, $\beta=.10, t(126)=1.08, p=.28 f^{2}=.01$. As hypothesized, the Nostalgia Proneness $\times$ Procedural Justice interaction predicted OCB, $\beta=-.18, t(126)=2.13, p=$ $.04, f^{2}=.04, R_{\text {change }}^{2}=.03$. Given that nostalgia proneness is a continuous variable, we probed this interaction using the Johnson and Neyman (1936) technique (Bauer \& Curran, 2005). This technique identifies for each value of the moderator (including customary values, such as $1 S D$ below and above the mean) whether the predictor significantly predicts the criterion variable. This technique, then, reveals the regions of nostalgia proneness where the association of procedural justice with OCB is significant and where it is not (Figure 2). For nostalgia proneness scores below 3.54, the association between procedural justice and OCB was significant. Furthermore, the relation between procedural justice and OCB was significant when nostalgia proneness was at 1 $S D$ below the mean, $\beta=.26, t(126)=2.14, p=.04, f^{2}=.06$, but was not significant when nostalgia proneness was at $1 S D$ above the mean, $\beta=-.08, t(126)=-.70, p=.47, f^{2}=.01$.

The previous analyses showed, consistent with Hypothesis 1, that the association between procedural justice and OCB was significant among employees low, but not high, in nostalgia proneness. However, Hypothesis 1 was more specific. It stated that high (compared to low) nostalgia would weaken the adverse influence of low procedural justice (rather than strengthen the positive influence of high procedural justice). This implies that, when procedural justice is low, employees who are high (compared to low) in nostalgia proneness should display increased levels of OCB. When procedural justice is high, however, employees' level of nostalgia proneness should not be associated with OCB. Visual inspection of the simple slopes (Figure 2) is 
consistent with this idea. As a formal test, we conducted further analyses using the Johnson and Neyman (1936) technique. We treated nostalgia proneness as the independent variable, procedural justice as the moderator, and OCB as the dependent variable. When procedural justice was low (i.e., scores below 2.95), employees who were high (compared to low) in nostalgia proneness evinced significantly higher levels of OCB. When procedural justice was high, nostalgia proneness was not significantly associated with OCB. Furthermore, when procedural justice was at $1 S D$ below the mean, employees who were high (compared to low) in nostalgia proneness evinced higher levels of $\mathrm{OCB}, \beta=.27, t(126)=2.34, p=.02 f^{2}=.06$. When procedural justice was at $1 S D$ above the mean, nostalgia proneness was not significantly associated with $\mathrm{OCB}, \beta=-.08, t(126)=-.65, p=.52, f^{2}=.01$. Hence, we observed particularly low levels of OCB when low procedural justice and low nostalgia proneness were juxtaposed.

\section{Discussion}

Study 1 demonstrated that the link between low (compared to high) procedural justice and reduced OCB is restricted to employees low in nostalgia proneness. This finding represents first evidence for our proposition that nostalgia accords members of social collectives the fortitude to cope with the averseness of low procedural justice. This evidence was obtained in a setting relevant to procedural justice processes, that is, in an organizational context in which employees reported on the fairness of decision making procedures regarding outcomes that matter to them, such as their salary and promotion opportunities.

A limitation of Study 1 is that the predictor variables, nostalgia and procedural justice, were assessed rather than manipulated. Thus, Study 1 cannot address adequately the causal ordering of variables. Furthermore, the survey methodology of Study 1 required the operationalizations of our constructs of interest to be broad. The established Colquitt (2001) measure does not specify the source of procedural justice or refer to a concrete event. Also, Podsakoff et al.'s (1990) instrument assesses overall reported OCB. This approach is in line with the vast majority of field studies addressing the relation between procedural justice and OCB (Cohen-Charash \& Spector, 2001; Colquitt et al., 2001, 3013). Adopting this approach allowed us to generalize our findings to the wider literature. In this survey context, it was 
appropriate to measure individual differences in nostalgia proneness. Yet, scholars have argued that research should also focus on source-specific responses to procedural justice and experiences of events of high or low justice (Cropanzano et al., 2001). ${ }^{1}$ Furthermore, a complete test of our propositions requires showing that the discrete emotion of nostalgia buffers the effect of low procedural justice on reduced cooperation.

\section{Study 2}

In Study 2, we tested the causal role of nostalgia in buffering lowered cooperation with a specific authority. We experimentally induced nostalgia (Wildschut et al., 2006) and manipulated procedural justice with the rule of voice in authority decisions (Van den Bos, 1999). Following prior experimental research (De Cremer \& Sedikides, 2005; De Cremer \& Van Knippenberg, 2002; De Cremer et. al. 2010), we operationalized cooperation as selfreported intentions to cooperate with the enacting authority.

Another objective of Study 2 was to find out if the buffering capacity of nostalgia derives merely from the positivity of nostalgic recollections. The content of nostalgic narratives is more positive than negative (Abeyta et al., in press; Wildschut et al., 2006), and nostalgia typically (Hepper et al., 2012; Stephan, Sedikides, \& Wildschut, 2012;Wildschut et al., 2006, 2010; Zhou, Wildschut, Sedikides, Shi, et al., 2012, Study 1) but not always (Turner, Wildschut, Sedikides, \& Gheorghiu, 2013; Zhou, Wildschut, Sedikides, Shi, et al., 2012, Studies 2-4) increases positive affect (PA). Although investigations have begun to establish unique effects of nostalgia above and beyond PA (Cheung et al., 2013; Routledge et al., 2012; Stephan et al., 2012, 2014; Turner, Wildschut, \& Sedikides, 2012, 2013; Van Tilburg, Igou, \& Sedikides, 2013), we needed to gauge the role of PA in the context of the current research. Hence, we unobtrusively assessed PA, as well as negative affect (NA), and tested whether the buffering role of nostalgia remains when controlling for these variables.

\section{Method}

Participants and design. Ninety-eight Dutch undergraduate business students (57 men, 41 women; $\left.M_{\text {age }}=21.69, S D_{\text {age }}=2.28\right)$ participated in exchange for course credit. They were randomly assigned to one of four conditions that resulted from orthogonally manipulating 
event reflection (nostalgia vs. ordinary) and procedural justice (low vs. high).

Procedure. Participants were seated in separate cubicles and received all information via computer. We used a validated nostalgia manipulation (Hepper et al., 2012; Wildschut et al., 2006). Participants in the nostalgia condition read:

According to the Oxford Dictionary, 'nostalgia' is defined as a 'sentimental longing for the past.' Please think of a nostalgic event in your life. Specifically, try to think of a past event that makes you feel most nostalgic. Bring this nostalgic experience to mind. Immerse yourself in the nostalgic experience. How does it make you feel? Please write down four keywords relevant to this nostalgic event (i.e., words that describe the experience).

Participants in the control condition read:

Please think of an ordinary event in your life. Specifically, try to think of a past event that is ordinary. Bring this ordinary experience to mind. Immerse yourself in the ordinary experience. How does it make you feel? Please write down four keywords relevant to this ordinary event (i.e., words that describe the experience).

In both conditions, after having written down the four keywords, participants were instructed to provide a narrative description of the recalled event. They then completed the nostalgia manipulation checks and were informed that they had reached the end of the study session.

After this, we surreptitiously introduced the procedural justice manipulation by either allowing or denying participants voice in a decision about an outcome that was relevant to them (Van Dijke et al., in press; for similar manipulations, see: Van den Bos, 1999; Van Prooijen, 2009). We told participants that we would like to request a few extra minutes of their time to engage in a brief selection procedure. The purpose of the procedure was to select one of the participants for a leadership position in a "group decision-making study" that would start a few weeks later. We mentioned that other students, who had previously taken part as leaders, found the experience highly rewarding. Moreover, leaders would receive extra course credit. We also stated that a research assistant (RA) would help with the selection procedure. The RA already had some basic information about each of them, and would send them a message about the selection. 
In the low procedural justice condition, participants received the following message, signaling they had no voice in the decision making process:

'Hi, I'm working on an assignment to determine who will be in charge of the group decision-making study that will run in a few weeks. To do so, I won't ask whether you think you should be the group leader or a group member.'

In the high procedural justice condition, participants received the following message signaling that they had voice in the decision making process:

'Hi, I'm working on an assignment to determine who will be in charge of the group decision-making study that will run in a few weeks. To do so, I'd like to know whether you think you should be the group leader or a group member. Please do not forget to communicate your choice to me.'

Then, participants in the high procedural justice condition indicated in a message to the RA whether they wanted to take part as a leader and a group member $(1=$ not at all, $7=$ very much $)$. Participants expressed a marginally stronger preference for being a leader $(M=5.19, S D=1.78)$ than a group member $(M=4.60, S D=1.59), F(1,51)=3.00, p=.09, \eta^{2}=.06$. These preferences were unaffected by the event reflection manipulation.

After participants waited for about $1 \mathrm{~min}$, they learned that the RA had compiled information and suggested suitable team leaders to the experimenters. Subsequently, participants were told that the selection procedure was finished and that they would receive an email in a few days informing them about the group decision study and their proposed role in it. They were also instructed that the experimenters were interested in what participants thought about the selection process, as this was the first time the RA was involved. Finally, they completed a procedural justice manipulation check and the key dependent measure of cooperative intentions.

Measures. We checked the event reflection manipulation using a 3-item scale (Wildschut et al., 2006). Participants rated the following items: "Right now, I am feeling quite nostalgic," "Right now, I am having nostalgic feelings," "I feel nostalgic at the moment" (1 = strongly disagree, $7=$ strongly agree; $M=4.50, S D=1.70 ; \alpha=.98)$. We checked the procedural justice manipulation by asking participants how "fair" and "just" (Van Dijke et al., 
in press) they regarded the way in which the RA had made the decision $(1=$ not at all, $7=$ very much so; $M=4.33$, $S D=1.60 ; \alpha=.88)$. We measured cooperative intentions with a 4item scale (Van Dijke et al., in press). Sample items are: "Would you be willing to help out the research assistant on future occasions?", "Do you intend to help the research assistant on future projects?" ( $1=$ not at all, $7=$ very much; $M=4.51, S D=1.46 ; \alpha=.92)$.

We assessed narrative positivity (PA; $M=5.61, S D=4.82)$ and negativity (NA; $M=$ $1.80, S D=2.75$ ) with the Linguistic Inquiry and Word Count software (LIWC; Pennebaker, Francis, \& Booth, 2001). LIWC checks each word and common word combination against an internal dictionary. Each word and word combination is assigned to one or more linguistic categories. The total number of words falling into each category is reported as a percentage to account for differences between participants in text length. ${ }^{2}$

\section{Results}

Manipulation checks. A one-way Analysis of Variance (ANOVA) with event reflection as independent variable and the nostalgia manipulation check as dependent variable revealed that, as intended, participants who recalled a nostalgic event $(M=5.41, S D=1.30)$ reported feeling more nostalgic than those who recalled an ordinary event $(M=3.73, S D=$ 1.63), $F(1,96)=31.06, p<.001, \eta_{p}^{2}=.24$. We did not include the procedural justice manipulation in this analysis, because we administered it after these checks.

An Event Reflection $\times$ Procedural Justice ANOVA on the procedural-justice manipulation check showed a significant main effect of procedural justice only. Participants in the low justice condition (i.e., those who were denied voice) reported lower justice ( $M=$ $3.58, S D=1.66$ ) compared to participants in the high justice condition (i.e., those who were granted voice $)(M=4.99, S D=1.20), F(1,94)=23.85, p<.001, \eta_{p}^{2}=.23$.

Cooperative intentions. An Event Reflection $\times$ Procedural Justice ANOVA yielded a significant main effect of procedural justice, $F(1,94)=11.57, p<.001, \eta_{p}^{2}=.11$. Participants in the low justice condition $(M=4.01, S D=1.58)$ reported weaker cooperative intentions than those in the high justice condition $(M=4.95, S D=1.18)$. We found no significant main effect of event reflection, $F(1,94)=1.79, p=.19, \eta_{p}^{2}=.02$. 
As anticipated, the main effect of procedural justice was qualified by a significant Event Reflection $\times$ Procedural Justice interaction, $F(1,94)=5.05, p=.03, \eta_{p}^{2}=.05$ (Figure 3). Simple effects analyses showed that, for control participants, low procedural justice $(M=$ 3.47, $S D=1.68)$ significantly weakened cooperative intentions relative to high procedural justice $(M=5.04, S D=1.12), F(1,94)=17.14, p<.001, \eta_{p}^{2}=.15$. However, for nostalgic participants, low procedural justice $(M=4.47, S D=1.35)$ did not significantly weaken cooperative intentions relative to high procedural justice $(M=4.79, S D=1.27), F(1,94)=$ $0.62, p=.43, \eta^{2}=.01$.

Similar to Study 1, we tested whether reflecting on a nostalgic (compared to ordinary) event weakens the adverse effect of low procedural justice (rather than strengthens the positive effect of high procedural justice). When procedural justice is low, nostalgic (compared to ordinary) reflection should thus increase cooperation. When procedural justice is high, however, nostalgic (compared to ordinary) reflection should not affect cooperation. (For a confirming visual inspection of the simple effects, see Figure 3.) In a formal test, we conducted simple effects analyses, in which we treated nostalgia as the independent variable and procedural justice as the moderator. In the low procedural justice condition, participants who recalled a nostalgic event $(M=4.47, S D=1.35)$ expressed stronger cooperative intentions than those who recalled an ordinary event $(M=3.47, S D=1.68), F(1,94)=6.17, p=.02, \eta_{p}^{2}=.06$. However, in the high procedural justice condition, there was no significant difference between those who recalled a nostalgic event $(M=4.80, S D=1.27)$ and those who recalled an ordinary event $(M=5.04, S D$ $=1.12), F(1,94)=0.43, p=.51, \eta_{p}^{2}=.01$. Consistent with Study 1 , we found particularly weak cooperative intentions when low procedural justice and low nostalgia were juxtaposed.

Controlling for PA and NA. Analyses in which we controlled for PA and NA and their interactions with procedural justice produced a significant Event Reflection $\times$ Procedural Justice interaction, $F(1,90)=5.05, p=.03, \eta_{p}^{2}=.05$. None of the control variables was significantly associated with cooperative intentions, $F \mathrm{~s}<1, p \mathrm{~s}>.54$.

\section{Discussion}

Low (compared to high) procedural justice reduced cooperative intentions towards the 
enacting authority for participants who recalled an ordinary event, but not for those who recalled a nostalgic event. These findings corroborated the corresponding ones from Study 1, supporting our proposed causal sequence. Furthermore, the role of nostalgia in buffering the negative effect of low (vs. high) procedural justice was not accounted for by variations in PA or NA. In all, Studies 1-2 provide converging field and laboratory evidence that nostalgia buffers the harmful impact of low procedural justice on cooperation.

\section{Study 3}

In Study 3, we addressed three key issues. First, we tested the process that explains why nostalgia buffers the adverse impact of low procedural justice on cooperation. We built our argument upon an established mediational model, according to which exposure to low (vs. high) procedural justice undermines social connectedness with the agent of low justice (i.e., an authority), which, in turn, predicts reduced cooperation (De Cremer \& Tyler, 2005; Tyler \& Blader, 2003). We proposed that, by virtue of its capacity to instill social connectedness, nostalgia helps individuals to cope with the experience of lowered connectedness to the specific authority. Therefore, we predicted that nostalgia buffers the negative impact of low (compared to high) procedural justice on support for the authority by blocking the path from social connectedness with the authority to support for the authority (Figure 1.

In addition, we included a different cooperation measure. So far, we followed existing research on the procedural justice-cooperation link by using OCB as our measure of cooperation in Study 1, and by using cooperative intentions as our measure of cooperation in Study 2. In Study 3, we informed participants that the researchers were in the process of deciding which of the RAs (i.e., the authority) to hire again for the upcoming academic year. We asked participants to make a recommendation to hire an RA or not.

Finally, we re-examined the possibility that PA may explain the role of nostalgia in buffering the negative effects of low procedural justice. In Study 2, we showed that the moderating role of nostalgia occurs independently of general PA (and NA), as indexed by LIWC-coded narratives. Whereas LIWC provides an objective means of examining implicit linguistic structure and emotion words (and bypasses demand characteristics), word-level 
coding cannot account for the meaning or context of the entire narrative, because each word is coded independently of all the others. Accordingly, LIWC may fail to capture fully the affective responses associated with recollecting nostalgic (vs. ordinary) events. We addressed this potential limitation by administering a self-report measure of PA.

\section{Method}

Participants and design. One hundred and twenty-three Dutch undergraduate business students (65 men, 58 women; $M_{\text {age }}=20.33$ years, $\left.S D_{\text {age }}=1.62\right)$ participated in exchange for course credit. They were randomly assigned to one of four conditions that resulted from orthogonally manipulating event reflection (nostalgia vs. ordinary) and procedural justice (low vs. high).

Procedure and measures. The procedure and measures were identical to Study 2, with three exceptions. First, immediately following the nostalgia manipulation check $(M=4.24, S D=$ $1.81 ; \alpha=.98$ ), we measured PA with the 10-item PA subscale of the PANAS (Watson, Clark, \& Tellegen, 1988; e.g., "interested," "excited"; 1 = very slightly or not at all, 7 = extremely; $M=3.96, S D=1.04 ; \alpha=.89)$. The item stem was: "Indicate to what extent you feel this way right now, that is, at the present moment." Second, immediately following the procedural justice manipulation check $(M=4.08, S D=1.52 ; \alpha=.93)$, we measured social connectedness with a 5-item scale (Hoogervorst, De Cremer, Van Dijke, \& Mayer, 2012). Sample items are: "To what extent do you feel connected to the research assistant?", "To what extent do you feel part of a team with the research assistant?" $(1=$ not at all, $7=$ very much so ; $M=3.45$, $S D=1.26 ; \alpha=.93)$. Third, after the assessment of social connectedness, we measured RA support with the following items: "Would you recommend that we hire this research assistant again in September?", "Do you consider this research assistant to be competent?" $(1$ = not at all, 7 = very much so). We also asked "What grade would you give this research assistant? The average grade that our research assistants get is a 7.1. Could you please give a grade between 1 and 10?" We standardized ( $z$ scores) these three items to create a common metric and combined them into a reliable index of RA support $(\alpha=.89)$. One participant did not grade the RA and was removed from the analyses. 


\section{Results and Discussion}

Manipulation checks. A one-way ANOVA with event reflection as independent variable and the nostalgia manipulation check as dependent variable revealed that, as intended, participants who recalled a nostalgic event $(M=5.04, S D=1.38)$ reported feeling more nostalgic than those who recalled an ordinary event $(M=3.60, S D=1.85), F(1,120)=$ $23.18, p<.001, \eta_{p}^{2}=.16$. We did not include the procedural justice manipulation in this analysis, because we administered it after these checks.

An Event Reflection $\times$ Procedural Justice ANOVA on the procedural-justice manipulation check produced a significant main effect of procedural justice only. Participants in the low procedural justice condition (i.e., those who were denied voice; $M=3.53, S D=$ 1.62) reported lower justice compared to those in the high procedural justice condition (i.e., those who were granted voice; $M=4.59, S D=1.22), F(1,118)=16.41, p<.001, \eta_{p}^{2}=.12$.

RA support. An Event Reflection $\times$ Procedural Justice ANOVA yielded a significant procedural justice main effect, $F(1,118)=12.10, p<.001, \eta_{p}^{2}=.09$. Participants in the low procedural justice condition $(M=-.32, S D=.96)$ reported lower RA support than those in the high procedural justice condition $(M=.23, S D=.67)$. The event reflection main effect was not significant, $F(1,118)=1.66, p=.20, \eta_{p}^{2}=.01$.

As anticipated, The procedural justice main effect was qualified by the Event Reflection $\times$ Procedural Justice interaction, $F(1,118)=4.16, p=.04, \eta_{p}^{2}=.03$ (Figure 4). Simple effects analyses showed that, for control participants, low procedural justice $(M=-.54, S D=1.02)$ significantly lowered RA support relative to high procedural justice $(M=.28, S D=.70), F(1$, $118)=16.36, p<.001, \eta_{p}^{2}=.12$. However, for nostalgic participants, low procedural justice $(M=-.04, S D=.82)$ did not significantly lower RA support relative to high procedural justice $(M=.17, S D=.65), F(1,118)=.99, p=.32, \eta_{p}^{2}=.01$.

We tested, as in Studies 1-2, whether nostalgia (compared to control) weakens the adverse effect of low procedural justice rather than strengthens the positive effect of high procedural justice. Inspection of the simple effects would indicate so (Figure 4). We conducted simple effects analyses, in which we treated nostalgia as the independent variable and procedural justice as the 
moderator. In the low procedural justice condition, nostalgic participants $(M=-.04, S D=.82)$ expressed stronger RA support than control participants $(M=-.54, S D=1.02), F(1,118)=$ $5.51, p=.02, \eta_{p}^{2}=.05$. In the high procedural justice condition, there was no significant difference between nostalgic $(M=.17, S D=.65)$ and an control $(M=.28, S D=.70)$ participants, $F(1,118)=.28, p=.60, \eta_{p}^{2}=.00$. Consistent with Studies $1-2$, we found particularly weak RA support when low procedural justice and low nostalgia were juxtaposed.

Controlling for PA. An analysis in which we controlled for PA and its interaction with procedural justice showed that the Event Reflection $\times$ Procedural Justice interaction remained significant, $F(1,116)=4.06, p=.046, \eta_{\mathrm{p}}^{2}=.03$. Neither of the two added independent variables was significantly associated with RA support, $F \mathrm{~s}<.09, p \mathrm{~s}>.76$.

Social connectedness. An Event Reflection $\times$ Procedural Justice ANOVA yielded a significant procedural justice main effect, $F(1,118)=34.94, p<.001, \eta^{2}=.23$. Participants in the low procedural justice condition $(M=2.84, S D=1.16)$ reported weaker social connectedness to the RA than those in the high procedural justice condition $(M=4.06, S D=$ 1.07). Neither the event reflection main effect, $F(1,118)=1.66, p=.20, \eta_{p}^{2}=.02$, nor the Event Reflection $\times$ Procedural Justice interaction, $F(1,118)=2.68, p=.10, \eta_{p}^{2}=.02$, was significant.

Moderated mediation analyses. We proceeded to test the moderated mediation model depicted in Figure 1. Edwards and Lambert (2007) referred to this model as direct effect and second stage moderation. We used the PROCESS macro to test the model (model 15; 5,000 resamples; Hayes, 2013). PROCESS calculates bootstrap confidence intervals (CIs) for the indirect effect (denoted as $a b$ ) of low (vs. high) procedural justice on RA support via social connectedness, conditional upon nostalgia (low vs. high). The indirect effect of procedural justice on RA support via social connectedness was significant among control participants, $a b$ $=.32,95 \% \mathrm{CI}: .14, .56$, but not among nostalgic participants, $a b=.13,95 \% \mathrm{CI}:-.08, .36$.

In conclusion, the results of Study 3 support the idea that nostalgia blunts the negative impact of low procedural justice on cooperation by weakening the link between reduced social connectedness and reduced cooperation, thus breaking the chain from justice to 
cooperation via social connectedness. We proceeded to fortify this empirical foundation in the next study.

\section{Study 4}

In Study 4, we pursued two objectives. To begin, we aimed to replicate and extend Studies 2-3 by using a behavioral measure of cooperation that implies voluntary effort on behalf of the authority (i.e., the RA). Given that volunteering to contribute time and effort on behalf of the RA implicates personal costs, a behavioral assessment of cooperation should be less susceptible to self-presentational concerns or experimental demand than the assessment of cooperative intentions and RA support in Studies 2-3. In addition, we aimed to assess the generalizability of the Study 3 findings. Having established that an experimental induction of nostalgia buffers the negative effect of low procedural justice, we examined if the moderated mediational model that received support in Study 3 (Figure 1) could be further validated when we measure nostalgia proneness (rather than manipulate state nostalgia).

Participants and design. One hundred and forty-one Dutch business students (102 men, 39 women; $M_{a g e}=20.01$ years, $\left.S D_{\text {age }}=1.45\right)$ participated in exchange for course credit. The design involved an assessment of nostalgia proneness (as a continuous independent variable) and an experimental manipulation of procedural justice (low vs. high).

Procedure. Participants were seated in separate cubicles and completed all materials on a computer. We assessed nostalgia proneness using the SNS $(M=4.56, S D=.95, \alpha=.89)$, as in Study 1 . Next, we manipulated procedural justice by randomly assigning participants to a low procedural justice (no voice) versus high procedural justice (voice) condition, as in Studies 23. Following the administration of the procedural justice manipulation check, we measured participants' social connectedness to the RA (i.e., the authority; see Study 3). We then introduced an anagram task that provided the context for assessing cooperation with the RA. The task comprised 100 anagrams, ranging from 3 to 6 letters. Participants learned that this task was part of the RA's Master's thesis on cognitive performance. They would not receive extra credit for engaging in this task and they were free to quit at any moment by clicking the stop button on their screen. By working on this task, participants would voluntarily help the RA with a project that 
was important to him (i.e., enabling him to obtain a Master's Degree).

Measures. As in Studies 2-3, we checked the procedural justice manipulation by asking how "fair" and "just" participants found the way in which the RA had made the decision $(1=$ not at all, $7=$ very much so; $M=3.64, S D=1.56, \alpha=.95)$. We measured social connectedness to the RA with the same a scale as in Study $3(1=$ not at all, $7=$ very much so; $M=3.42, S D=$ $1.29, \alpha=.91)$. Finally, the dependent variable comprised the number of anagrams that participants solved correctly $(M=22.11, S D=18.52)$.

\section{Results and Discussion}

We analyzed the data using a moderated regression approach. We regressed the dependent variables onto the procedural justice manipulation (contrast coded: $-1=$ high procedural justice, 1 $=$ low procedural justice), nostalgia (mean centered), and the Nostalgia Proneness $\times$ Procedural Justice interaction.

Manipulation check. A regression analysis produced a significant procedural justice main effect, $\beta=-.68, t(136)=-10.86, p<.001, f^{2}=.85$. Participants in the low procedural justice condition $(M=2.83, S D=1.13)$ indeed reported lower procedural justice compared to those in the high procedural justice condition $(M=5.03, S D=1.18)$. Neither the nostalgia proneness main effect, $\beta=.04, t(136)=.41, p=.68, f^{2}=.00$ nor the Nostalgia Proneness $\times$ Procedural Justice interaction, $\beta=.05, t(136)=0.78, p=.43, f^{2}=.01$, was significant.

Cooperation. A regression analysis produced a significant Nostalgia Proneness $\times$ Procedural Justice interaction, $\beta=-.190, t(136)=-2.21, p=.03, f^{2}=.04$ (Figure 5). The interaction conceptually replicated results from the preceding studies. We probed it with the Johnson and Neyman (1936) technique. For nostalgia proneness scores below 3.24, participants who perceived low procedural justice (i.e., those who were denied voice) were significantly less likely to display cooperation than participants who perceived high procedural justice (i.e., those who received voice). The regions of significance analysis also revealed that the effect of procedural justice on cooperation was marginal when nostalgia proneness was at $1 S D$ below the mean, $\beta=.22, t(136)=1.80, p=.07, f^{2}=.02$, but not when nostalgia proneness was at $1 S D$ above the mean; $\beta=-.15, t(136)=-1.27, p=.21, f^{2}=.00$. 
Next, we tested whether high (compared to low) nostalgia proneness is associated with weakening of the adverse effect of low procedural justice rather than strengthening of the positive effect of high procedural justice. (For a confirming visual inspection, see Figure 5.) We conducted simple slopes analyses with OLS regression, in which we treated nostalgia as the independent variable and procedural justice as the moderator. For participants in the low procedural justice condition, nostalgia proneness was positively, albeit marginally, related to cooperation, $\beta=.20$, $t(136)=1.70, p=.09, f^{2}=.02$. However, for participants in the high procedural justice condition, nostalgia proneness was not significantly related to cooperation, $\beta=-.18, t(136)=-1.4, p=.15, f^{2}$ $=.01$. As in Studies 1-3, participants evinced low levels of cooperation at the juxtaposition of low procedural justice and low nostalgia proneness.

Social connectedness. A regression analysis yielded only a significant procedural justice main effect, $\beta=-.48, t(136)=-6.45, p<.001, f^{2}=.30$. As hypothesized, participants in the low procedural justice condition $(M=2.94, S D=1.13)$ reported weaker social connectedness to the RA than those in the high procedural justice condition $(M=4.24, S D=$ 1.12). Neither the nostalgia proneness main effect, $\beta=.06, t(136)=0.83, p=.41, f^{2}=.01$, nor the Nostalgia Proneness $\times$ Procedural Justice interaction, $\beta=-.01, t(136)=-0.14, p=.89$, $f^{2}=.00$, was significant. These results mirror those obtained in Study 3 by showing that exposure to low (vs. high) procedural justice undermines social connectedness with the authority figure.

Moderated mediation analyses. As in Study 3, we used the PROCESS macro to test our model (model 15; 5,000 resamples; Hayes, 2013). For low nostalgia proneness, we took the cut-off value from the Johnson and Neyman (1936) technique (i.e., 3.24). For high nostalgia proneness, we took the value with the same distance from the mean as the low nostalgia proneness value (i.e., 5.89). We obtained a significant indirect effect of procedural justice on cooperation via social connectedness among low nostalgia proneness participants, $a b=4.03$, 95\% CI: 1.50, 6.98, but not among high-nostalgia proneness participants, $a b=.17,95 \% \mathrm{CI}$ : $2.05,1.93 .^{3}$

In conclusion, these results replicate and extend the Study 3 findings. Study 4 provides 
vital corroborating evidence for the idea that high nostalgia buffers the negative impact of low procedural justice on cooperation by weakening the link between reduced social connectedness and reduced cooperation.

\section{Study 5}

We set two objectives in Study 5. First, we examined the discriminant validity of the Studies 3-4 findings. As we noted in the Introduction, members may value procedural justice not only for affiliative reasons (i.e., fulfilment of connectedness needs), but also for deontic reasons (procedural justice as a moral principle) and instrumental reasons (facilitation of longterm personal goals). Deontic and instrumentality concerns may mediate the effect of procedural justice on cooperation, with evidence that instrumental concerns do so (Cropanzano et al., 2001). If nostalgia helped individuals cope with low procedural justice by blocking the path from reduced social connectedness to cooperation specifically, and not by blocking the paths from instrumentality and deontic anger to cooperation, these patterns would support our claim that the buffering role of nostalgia derives from its capacity to instill social connectedness. Second, we tested whether the role of nostalgia in buffering harmful effects of low procedural justice on cooperation generalizes beyond a composite index of procedural rules (Study 1) and the rule of voice in the decision of an authority (Studies 2-4) to the accuracy with which an authority makes a decision (De Cremer, 2004).

Participants and design. We recruited participants via MTurk and paid them $\$ 0.85$. To increase our confidence that participants identified with the vignette (described below), inclusion criteria stated that they be employed in an organization and have a supervisor. One hundred and seventy-three respondents (of 180; 96\%) met these criteria (97 men, 76 women; $\left.M_{\text {age }}=35.11, S D_{\text {age }}=11.70\right)$. On average, participants had worked in their current organization for 5.09 years $(S D=3.99)$. Twenty-two percent of them had completed secondary education only, $12 \%$ subsequent vocational training, $49 \%$ a Bachelor's degree, 15\% a Master's degree, and 2\% a Doctoral degree. Participants were randomly assigned to one of four conditions that resulted from orthogonally manipulating event reflection (nostalgia vs. ordinary) and procedural justice (low vs. high). 
Procedure and measures. Participants were asked to take part in two separate studies. The first was ostensibly about personal experiences, and it consisted of our nostalgia (vs. control) manipulation (as in Studies 2-3). We administered the same nostalgia manipulation check as in Studies 2-3 $(M=4.57, S D=1.80, \alpha=.99)$. Next, we told participants that, following completion of the first study, they would be automatically forwarded to the second one. We then manipulated procedural justice via the accuracy rule (De Cremer, 2004). In line with research showing that connectedness concerns are relevant to individuals even in imagined situations (Leary, Haupt, Strausser, \& Chokel, 1998), we asked participants to imagine that they worked for a company and took part in an internal selection procedure to acquire a higher position. Participants would take nine tests, and their supervisor would base his decision on the test outcome. Half of participants learned that their supervisor had graded all nine tests (high procedural justice), whereas the other half learned that he had graded only one test (low procedural justice).

We checked the procedural justice manipulation with the same two items as in Studies 2-4 ( 1 = not at all, $5=$ very much so; $M=2.95, S D=1.35, \alpha=.97)$. We measured social connectedness to the supervisor with the same 5-item scale as in Studies 3-4 (1 = not at all, 5 $=$ very much so $M=2.94, S D=1.06, \alpha=.95)$. We measured instrumentality with an 8-item scale (Shore, Tetrick, Lynch, \& Barksdale, 2006), which we adapted by changing the referent from "the organization" to "your supervisor.". Sample items are: "I don't mind working hard today — knowing that I will eventually be rewarded by my supervisor," "There is a lot of give and take in the relationship with my supervisor" $(1=$ strongly disagree, $5=$ strongly agree; $M$ $=3.15, S D=.91, \alpha=.92$ ). We measured deontic anger with a four-item scale (Lodewijkx, Kersten, \& Van Zomeren, 2008). Sample items are "Do you find your supervisor's behavior immoral?", "Are you angry at your supervisor?" $(1=$ not at all, $5=$ very much so; $M=2.48$, $S D=1.23, \alpha=.91)$. We measured cooperation with the same three items as in Study 3. In introducing the items, we noted that the company's top management was considering an extension to the supervisor's contract and was interested in the participants' opinion. As in Study 3, we standardized responses ( $z$ scores) to create a common metric and combined them into an index of supervisor support $(\alpha=.90)$. 


\section{Results and Discussion}

Manipulation checks. A one-way ANOVA with event reflection as independent variable and the nostalgia manipulation check as dependent variable revealed that participants who recalled a nostalgic event $(M=5.75, S D=.98)$ reported feeling more nostalgic than those who recalled an ordinary event $(M=3.54, S D=1.71), F(1,71)=105.15, p<.001, \eta_{p}^{2}=$ .38. We did not include the procedural justice manipulation in this analysis, because we administered it after these checks.

An Event Reflection $\times$ Procedural Justice ANOVA on the procedural justice manipulation check produced a significant procedural justice main effect (low procedural justice: $M=1.87, S D=1.03$; high procedural justice: $M=3.90, S D=.75 ; F[1,169]=210.01$, $\left.p<.001, \eta_{p}^{2}=.55\right)$. The event reflection manipulation main effect was also significant. Participants who recalled a nostalgic event $(M=3.22, S D=1.29)$ reported higher procedural justice than those who recalled an ordinary event $(M=2.71, S D=1.36), F(1,71)=4.60, p=$ $.03, \eta_{p}^{2}=.03$. The Event Reflection $\times$ Procedural Justice interaction was not significant, $F(1$, 169) $=.78, p=.38, \eta_{p}^{2}=.01$.

Supervisor support. An Event Reflection $\times$ Procedural Justice ANOVA yielded a significant procedural justice main effect, $F(1,169)=145.19, p<.001, \eta_{p}^{2}=.46$. Participants in the low procedural justice condition $(M=-.60, S D=.77)$ reported weaker supervisor support than those in the high procedural justice condition $(M=.60, S D=.53)$. The event reflection main effect was also significant, $F(1,169)=11.68, p=.001, \eta_{p}^{2}=.07$. Participants who recalled a nostalgic event $(M=.27, S D=75)$ reported higher supervisor support than those who recalled an ordinary event $(M=-.16, S D=.95)$.

Importantly, the procedural justice main effect was qualified by the Event Reflection $\times$ Procedural Justice interaction, $F(1,169)=11.37, p=.001, \eta_{p}^{2}=.06$ (Figure 6). Simple effects analyses showed that, for control participants, low procedural justice $(M=-.86, S D=.72)$ significantly attenuated supervisor support relative to high procedural justice $(M=.60, S D=$ $.45), F(1,169)=129.27, p<.001, \eta_{p}^{2}=.43$. For nostalgic participants, low procedural justice $(M=-.22, S D=.68)$ also significantly attenuated supervisor support relative to high 
procedural justice $(M=.61, S D=.60)$, but this effect was much weaker, $F(1,169)=34.85, p$ $<.001, \eta_{p}^{2}=.17$.

Similar to Studies 1-4, we tested whether reflecting on a nostalgic (compared to ordinary) event weakens the adverse effect of low procedural justice rather than strengthens the positive effect of high procedural justice. A visual inspection of the simple effects would appear to show that this is indeed the case (Figure 6). Consistent with Studies 1-4, in the low procedural justice condition, nostalgic participants $(M=-.22, S D=.68)$ expressed stronger supervisor support than control participants $(M=-.86, S D=.72), F(1,169)=21.35, p<.001, \eta_{p}^{2}=.11$. In the high procedural justice condition, there was no significant difference between nostalgic $(M=$ $.60, S D=.45)$ and control $(M=.61, S D=.60)$ participants, $F(1,169)=.001, p=.97, \eta_{p}^{2}=$ .00. As in Studies 1-4, members evinced particularly weak supervisor support at the juxtaposition of low procedural justice and low nostalgia.

Social connectedness. An Event Reflection $\times$ Procedural Justice ANOVA yielded a significant procedural justice main effect, $F(1,169)=85.19, p<.001, \eta^{2}=.34$. Participants in the low procedural justice condition $(M=2.27, S D=.94)$ reported weaker social connectedness to the supervisor than those in the high procedural justice condition $(M=3.54$, $S D=.79)$. The event reflection main effect, $F(1,169)=3.65, p=.06, \eta_{p}^{2}=.02$, and the Event Reflection $\times$ Procedural Justice interaction, $F(1,169)=.40, p=.53, \eta_{p}^{2}=.00$, were not significant.

Instrumentality. An Event Reflection $\times$ Procedural Justice ANOVA yielded a significant procedural justice main effect, $F(1,169)=55.27, p<.001, \eta^{2}=.25$. Participants in the low procedural justice condition $(M=2.66, S D=.90)$ reported weaker instrumentality than those in the high procedural justice condition $(M=3.59, S D=.67)$. The event reflection main effect was also significant, $F(1,169)=10.45, p=.001, \eta_{p}^{2}=.06$. Nostalgic participants $(M=3.40, S D=.80)$ reported stronger instrumentality than control participants $(M=2.93, S D$ $=.95)$. The Event Reflection $\times$ Procedural Justice interaction, $F(1,169)=2.01, p=.16, \eta_{p}^{2}=$ .01 , was not significant.

Deontic anger. An Event Reflection $\times$ Procedural Justice ANOVA yielded a significant 
procedural justice main effect, $F(1,169)=128.01, p<.001, \eta^{2}=.43$. Participants in the low procedural justice condition $(M=3.35, S D=.93)$ reported more intense deontic anger than those in the high procedural justice condition $(M=1.72, S D=.90)$. Neither the event reflection main effect, $F(1,169)=3.16, p=.08, \eta_{p}^{2}=.02$, nor the Event Reflection $\times$ Procedural Justice interaction, $F(1,169)=.16, p=.69, \eta_{p}^{2}=.00$, was significant.

Moderated mediation analyses. We tested the moderated mediation model depicted in Figure 1, using the PROCESS macro (model 15, 5,000 resamples; Hayes, 2013). We simultaneously entered social connectedness, instrumentality, and deontic anger as mediators. The indirect effect of procedural justice on supervisor support via social connectedness was significant among control participants, $a b=.26,95 \% \mathrm{CI}: .05, .56$, but not among nostalgic participants, $a b=.01,95 \% \mathrm{CI}:-.23, .23$. However, the indirect effects of procedural justice on supervisor support via instrumentality and via deontic anger were significant among both control $(a b=.28,95 \%$ CI: $.10, .46 ; a b=.39,95 \%$ CI: $.16, .71$ respectively) and nostalgic $(a b$ $=.48,95 \%$ CI: $.28, .77 ; a b=.29,95 \% \mathrm{CI} . .08, .52$ respectively) participants.

Supplemental analyses. In Study 5 we also measured nostalgia proneness with the SNS, as in Studies 1 and 4. Given that scores on this scale may influence responses to the nostalgia manipulation, we redid all the above analyses while controlling for the SNS. The results were identical to the ones we presented above.

In conclusion, the Study 5 findings are consistent with the idea that nostalgia blunts the negative impact of low procedural justice on cooperation by specifically weakening the link between reduced social connectedness and reduced cooperation.

\section{General Discussion}

We demonstrated across five studies that nostalgia buffers the deleterious impact of low procedural justice on cooperation. We obtained evidence for this role of nostalgia both in a naturalistic setting (employees in organizations - Study 1) and a controlled setting (Studies 25). We also garnered evidence for the buffering role of nostalgia when procedural justice was operationalized either in general terms (as aspects of the decision-making procedure-Study 1) or in specific terms (as the procedural rule of voice in an authority's decisions-Studies 2- 
4 or as an authority's accuracy in making a decision-Study 5). Moreover, the buffering role of nostalgia emerged regardless of whether nostalgia was operationalized in terms of an experimentally induced emotional state (Studies 2, 3, and 5) or as chronic individual differences in nostalgia proneness (Studies 1 and 4). Finally, nostalgia buffered the harmful effect of low procedural justice on self-reported cooperation (i.e., OCB-Study 1), on intentions to cooperate (Study 2), on support for the authority (Study 3 and 5), and on objective cooperative behavior (Study 4).

Crucially, our research shows why nostalgia buffers the negative impact of low procedural justice on cooperation. Building on prior work (De Cremer \& Tyler, 2005; Lind \& Tyler, 1988), we found that low procedural justice reduced the degree to which individuals felt socially connected with the relevant authority figure. This drop in social connectedness undermined support for the authority (Study 3 and 5) and cooperative behavior that would benefit the authority (Study 4) when nostalgia (induced or measured) was low but not when it was high. Additionally, Study 5 showed that nostalgia does not affect the role of two other theoretically relevant variables that have been purported to mediate the effect of procedural justice on cooperation, that is, instrumentality and deontic anger. Thus, nostalgia afforded individuals the fortitude to cooperate with the authority despite experiencing reduced social connectedness to this person.

\section{Implications}

Our findings contribute to the procedural justice literature. Previous research has established that low procedural justice quells cooperation among members of a collective. Yet, understanding of the mechanisms that account for this relation, and especially of processes that can buffer it, is limited (Blader \& Tyler, 2005; Colquitt et al., 2005). Emotions may constitute such a buffer, although there is a dearth of knowledge about such a role for emotions (Colquitt et al., 2013; Cropanzano et al., 2011). Relational justice models note that procedural justice promotes cooperation because it communicates information about one's connectedness to the collective or an authority (De Cremer \& Tyler, 2005; Tyler \& Blader, 2003), and this threatens the need to belong (De Cremer \& Blader, 2006). In line with the 
relevant literature (Baumeister, 2012), we argued that, if the need to belong is satisfied (e.g., by experiencing nostalgia), specific instances of threatened connectedness, such as resulting from low procedural justice, are less damaging and less in need of a response. Our findings thus integrate the workings of nostalgia with relational models of justice and allow these models to predict how individuals cope with low procedural justice.

Our findings also contribute to the nostalgia literature. Research has established nostalgia's capacity to counteract unpleasant affect (Wildschut et al., 2006), negative performance feedback (Vess, Arndt, Routledge, Sedikides, \& Wildschut, 2012, boredom (Van Tilburg et al., 2013), loneliness (Zhou et al., 2008), perceived discontinuity between one's past and present life (Sedikides, Wildschut, Routledge, \& Arndt, in press), and existential insecurities (Routledge et al., 2011). Yet, this is the first time that research has documented nostalgia's capacity to buffer against organizational adversity (i.e., low procedural justice and its resultant reduced social connectedness with authorities), thereby facilitating prosocial behavior within the organization (i.e., cooperation with the authority) even in adverse situations. Furthermore, our research also offers compelling evidence that this results from nostalgia's role as repository of social connectedness.

Our findings raise broader implications for understanding organizational processes. Members may gain remarkable benefits from organizations (personal, social, monetary), but organizational membership also entails frequent experiences of low procedural justice (Johnson et al., 2014) and, consequentially, compromised connectedness (De Cremer \& Tyler, 2005; Tyler \& Blader, 2003). Low procedural justice increases the likelihood of retaliation, passive withdrawal, or organizational exit (Ambrose et al., 2002; Colquitt et al. 2013). However, such responses can undermine the employees' own interests and, accordingly, many employees must cope with low procedural justice while maintaining their cooperativeness. Our research indicates that nostalgia constitutes an indirect strategy for coping with low procedural justice—a strategy that sustains cooperativeness.

Whereas a minor instance of low procedural justice during a regular workday may not evoke strong nostalgia, major incidents such as lay-offs may evoke vivid nostalgic 
recollections of a better past. Particularly in this latter type of situation, low procedural justice is harmful to employees and organizations. Yet, research indicates that displaying high procedural justice drains managers' cognitive resources, making it difficult to enact fair procedures consistently (Johnson et al., 2014). Thus, nostalgizing in situations in which procedural justice may be compromised (e.g., lay-offs, organizational mergers) may be an effective coping strategy. Our findings indicate that nostalgia is relatively easy to induce. As such, nostalgia can be an integral part of programs to support organizational members during times of organizational hardship (e.g., austerity measures, reorganizations, lay-offs).

Stimulating nostalgia may seem cynically self-serving from the perspective of organizations, but cooperation also facilitates employee career advancement (Podsakoff et al., 2009). Thus, nostalgia may also benefit employees and, at the very least, help them to cope with unavoidable injustice.

The pilot study (Footnote 1) showed that employees' nostalgic recollections rarely relate to shared organizational experiences with colleagues or authorities. Our findings thus create an interesting contrast with research addressing the relation between work and nonwork (e.g., leisure, family) spheres. The vast majority of this work (i.e., in the work-home and home-work interference literatures) has shown that positive outcomes in one domain lead to negative outcomes in the other domain. Some studies have taken a more favorable outlook on the relation between work and non-work spheres, but these studies have usually considered main effects, demonstrating for instance that a satisfying family life can also increase job satisfaction (McNall, Nicklin, \& Masuda, 2010). We know of only one study suggesting that non-work spheres can buffer adverse organizational circumstances. Barnett, Marshall, and Pleck (1992) reported in a cross-sectional survey that the relation between work stress and impaired well-being was attenuated for men who had a more satisfying family life. By illustrating how nostalgia buffers the negative effect of low procedural justice on cooperation (i.e., by blocking the path from social connectedness to cooperation), our research identifies a mechanism capable of explaining how non-work spheres may buffer organizational adversity.

\section{Limitations and Suggestions for Future Investigations}


We wish to acknowledge several limitations, which could provide the impetus for follow-up investigations. First, in Study 5, we manipulated procedural justice in a vignette. However, this vignette is known to elicit responses and perceptions similar to real experiences of high versus low procedural justice (De Cremer, 2004). More important, the vignette is relevant to our research questions, as connectedness concerns drive psychological responses even in imaginary situations (Leary et al., 1998). In all, we obtained similar effects in the field (Study 1), the laboratory (Studies 2-4), and a vignette (Study 5). This convergence increases our confidence in the robustness of the effects.

Our use of self-reported cooperative intentions in Study 2 may also be the subject of criticism. We included this dependent variable in one of our studies, because almost all laboratory research addressing the effect of procedural justice on cooperation has used selfreported intentions as outcome measure (De Cremer \& Sedikides, 2005; De Cremer \& Van Knippenberg, 2002; De Cremer et al, 2010). Our choice thus facilitates integration of our findings with the literature. Given the potential limitations associated with the use of selfreported cooperative intentions (Van Dijke et al., in press), we operationalized cooperation in terms of OCB (Study 1), cooperative intentions (Study 2), support for the authority (Studies 3 and 5), and cooperative behavior (Study 4). This methodological diversity allows individual studies to borrow strength from each other and underpins confidence in their findings (Campbell \& Fiske, 1959).

Our focus on cooperation, though, may be considered a limitation. Although this is a crucial variable in organizational contexts, and low procedural justice is a well-established antecedent of reduced cooperation (Cohen Charash \& Spector, 2001; Colquitt et al., 2001), cooperation is not the only crucial outcome of low procedural justice. For example, some behaviors are aimed at harming the collective and its representatives. Such behaviors are fairly common (Ambrose et al., 2002), and low procedural justice increases the probability of enacting them (Colquitt et al., 2013). As another example, low procedural justice is associated with heightened stress among organization members (Judge \& Colquitt, 2004). Nostalgia may buffer or disrupt the deleterious effect of low procedural justice on organizationally 
destructive behaviors and members' stress, and this would constitute a promising line of inquiry. However, the effects of procedural justice on other key outcome variables, such as trust in authorities, may not be mediated by connectedness (Colquitt \& Greenberg, 2005). Future research should establish boundary conditions to the role of nostalgia by assessing which effects of low procedural justice are not buffered by nostalgia.

We showed that nostalgia helps individuals cope with low procedural justice; yet, we did not show that individuals recruit nostalgia to help them cope with low procedural justice. As with any emotion (Frijda, 2000), nostalgia may be regarded a momentary state that is triggered by specific circumstances (Routledge et al., 2013; Wildschut et al., 2006). Negative affect and loneliness (i.e., a chronic lack of connectedness) elicit nostalgia (Wildschut et al., 2006; Zhou et al., 2008). Both antecedents are relevant to our theoretical orientation. Low procedural justice elicits negative affect (Colquitt et al., 2013) and communicates threatened connectedness (De Cremer \& Blader, 2006; Van Dijke \& De Cremer, 2008). This suggests that, although the effects of nostalgia are likely short-lived, nostalgia may be recruited in specific instances in which connectedness is threatened. Future research should address whether individuals recruit nostalgia to cope with low procedural justice and what the longterm role of nostalgia is in offsetting this aversive experience.

Our reliance on the well-known Colquitt (2001) scales and established manipulations of procedural justice implies that, in line with the literature, we focused on modest experiences of low (vs. high) procedural justice at the neglect of extreme injustice and extreme justice (Gilliland, 2008). Follow-up research should address whether nostalgia can also buffer the negative ramifications of extreme injustice. Relatedly, our research focused on the role of nostalgia in buffering the effect of low procedural justice. New research should test whether nostalgia also buffers negative effects of other types of injustice and, in particular, the interpersonal treatment that organizational members receive as procedures are enacted (i.e., interactional injustice; (Bies \& Moag, 1986). Finally, in Studies 1-4 (but not in Study 5), when nostalgia was heightened, high (relative to low) procedural justice lowered cooperation (albeit non-significantly so), an effect that needs more detailed examination. ${ }^{4}$ 


\section{Concluding Remarks}

The ability to pull toward a common goal is one of the finest human strengths. This is one reason why investigations into (low) procedural justice - as an influential antecedent of the (un)willingness to display collectively oriented behavior-is ongoing. By integrating nostalgia with procedural justice models, we demonstrated that nostalgia can play a key role in maintaining effective group and organizational functioning in the presence of low procedural justice. We hope that our findings spark further efforts toward integration between the emotion and procedural justice literatures. 


\section{References}

Abeyta, A., Routledge, C., Sedikides, C., \& Wildschut, R. T. (in press). Attachment-related avoidance and the social content of nostalgic memories. Journal of Social and Personal Relationships.

Ambrose, M. L., Seabright, M. A., \& Schminke, M. (2002). Sabotage in the workplace: The role of organizational injustice. Organizational Behavior and Human Decision Processes, 89, 947-965.

Aquino, K., \& Douglas, S. (2003). Identity threat and antisocial behavior in organizations: The moderating effects of individual differences, aggressive modeling, and hierarchical status. Organizational Behavior and Human Decision Processes, 90, 195-208.

Barnett, R. C, Marshall, N. L., \& Pleck, J. H. (1992). Men's multiple roles and their relationship to men's psychological distress. Journal of Marriage and the Family, 54, 358-367.

Barrett, F. S., Grimm, K. J., Robins, R. W., Wildschut, T., Sedikides, C., \& Janata, P. (2010). Music-evoked nostalgia: Affect, memory, and personality. Emotion, 10, 390-403.

Batcho, K. I., (2013). Nostalgia: The bittersweet history of a psychological concept. History of Psychology, 16, 165-176.

Bauer, D. J., \& Curran, P. J. (2005). Probing interactions in fixed and multilevel regression: Inferential and graphical techniques. Multivariate Behavioral Research, 40, 373-400.

Baumeister, R. F. (2012). Need-to-belong theory. In P. van Lange, A. Kruglanski, \& T. Higgins (Eds.), Handbook of theories of social psychology (pp. 121-140). London, UK: Sage.

Bies, R. J., \& Moag, J. F. (1986). Interactional justice: Communication criteria of fairness. In R. J. Lewicki, B. H. Sheppard, \& M. H. Bazerman (Eds.), Research on negotiations in organizations (Vol. 1, pp. 43-55). Greenwich, CT: JAI Press.

Blader, S., \& Tyler, T. (2009). Testing and extending the group engagement model: Linkages between social identity, procedural justice, economic outcomes, and extrarole behavior. Journal of Applied Psychology, 94, 445-464.

Boym, S. (2001). The future of nostalgia. New York, NY: Basic Books.

Campbell, D. T., \& Fiske, D. W. (1959). Convergent and discriminant validation by the multitrait- 
multimethod matrix. Psychological Bulletin, 56, 81-105.

Carpenter, N. C., Berry, C. M., \& Houston, L. (2014). A meta-analytic comparison of selfreported and other-reported organizational citizenship behavior. Journal of Organizational Behavior, 35, 547-574.

Cheung, W. Y., Wildschut, T., Sedikides, C., Hepper, E. G., Arndt, J., \& Vingerhoets, A. J. J. M. (2013). Back to the future: Nostalgia increases optimism. Personality and Social Psychology Bulletin, 39, 1484-1496.

Cohen, J. (1988). Statistical power analysis for the behavioral sciences. Second edition. Hillsdale, NJ : Lawrence Erlbaum Associates.

Cohen-Charash, Y., \& Spector, P. E. (2001). The role of justice in organizations: A meta-analysis. Organizational Behavior and Human Decision Processes, 86, 278-321.

Colquitt, J. A. (2001). On the dimensionality of organizational justice: A construct validation of a measure. Journal of Applied Psychology, 86, 386-400.

Colquitt, J. A., Conlon, D. E., Wesson, M. J., Porter, C. O. L. H., \& Ng, K. Y. (2001). Justice at the millennium: A meta-analytic review of 25 years of organizational justice research. Journal of Applied Psychology, 86, 425-445.

Colquitt, J. A., Scott, B. A., Rodell, J. B., Long, D. M., Zapata, C. P., Conlon, D. E., \& Wesson, M. J. (2013). Justice at the millennium, a decade later: A meta-analytic test of social exchange and affect-based perspectives. Journal of Applied Psychology, 98, 199-236.

Cropanzano, R., Byrne, Z. S., Bobocel, D. R., \& Rupp, D. E. (2001). Moral virtues, fairness heuristics, social entities, and other denizens of organizational justice. Journal of Vocational Behavior, 58, 164-209.

Cropanzano, R., Stein, J. H., \& Nadisic, T. (2011). Social justice and the experience of emotion. New York, NY: Routledge.

De Cremer, D. (2004). The influence of accuracy as a function of leader's bias: The role of trustworthiness in the psychology of procedural justice. Personality and Social Psychology Bulletin, 30, 293-304.

De Cremer, D., \& Blader, S. (2006). Why do people care about procedural fairness? The 
importance of belongingness in responding and attending to procedures. European Journal of Social Psychology, 36, 211-228.

De Cremer, D., \& Tyler, T. R. (2005). Managing group behavior: The interplay between procedural justice, sense of self, and cooperation. Advances in Experimental Social Psychology, 37, 151-218.

Edwards, J. R., \& Lambert, L. S. (2007). Methods for integrating moderation and mediation: A general analytical framework using moderated path analysis. Psychological Methods, 12, 122.

Frijda, N. H. (2000). The psychologists' point of view. In M. Lewis \& J. M. Haviland-Jones (Eds.), Handbook of emotions (2nd ed., pp. 59-74). New York: Guilford Press.

Gardner, W. L., Pickett, C. L., \& Knowles, M. L. (2005). Social snacking and shielding: Using social symbols, selves, and surrogates in the service of belongingness needs. In K. D. Williams, J. P. Forgas, \& W. von Hippel (Eds.), The social outcast: Ostracism, social exclusion, rejection, and bullying (pp. 227-241). New York, NY: Psychology Press.

Gilliland, S. (2008). The tails of justice: A critical examination of the dimensionality of organizational justice constructs. Human Resource Management Review, 18, 271-281.

Hayes, A. F. (2013). Introduction to mediation, moderation, and conditional process analysis. New York, NY: Guilford.

Hepper, E. G., Ritchie, T. D., Sedikides, C., \& Wildschut, T. (2012). Odyssey's end: Lay conceptions of nostalgia reflect its original Homeric meaning. Emotion, 12, 102-119.

Hepper, E. G., Wildschut, T., Sedikides, C., Ritchie, T. D., Yung, Y.-F., Hansen, N., ... \& Zhou, X. (2014). Pancultural nostalgia: Prototypical conceptions across cultures. Emotion, 14, 733747.

Holak, S. L., \& Havlena, W. J. (1992). Nostalgia: An exploratory study of themes and emotions in the nostalgic experience. In J. F. Sherry, Jr. \& B. Sternthal (Eds.), Advances in consumer research (Vol. 19, pp. 380-387). Provo, UT: Association for Consumer Research.

Hoogervorst, N., De Cremer, D., Van Dijke, M. H., Mayer, D. M. (2012). When do leaders sacrifice? The effects of sense of power and belongingness on leader self-sacrifice. 
Leadership Quarterly, 23, 883-896.

Johnson, R. E., Lanaj, K., \& Barnes, C. M. (2014). The good and bad of being fair: Effects of procedural and interpersonal justice behaviors on regulatory resources. Journal of Applied Psychology. 99, 635-650.

Johnson, P. O., \& Neyman, J. (1936). Tests of certain linear hypotheses and their application to some educational problems. Statistical Research Memoirs, 1, 57-93.

Judge, T. A., \& Colquitt J. A. (2004). Organizational justice and stress: The mediating role of work-family conflict. Journal of Applied Psychology, 89, 395-404.

Juhl, J., Routledge, C., Arndt, J., Sedikides, C., \& Wildschut, T. (2010). Fighting the future with the past: Nostalgia buffers existential threat. Journal of Research in Personality, 44, 309-314.

Leary, M. (2005). Interpersonal cognition and the quest for social acceptance: Inside the sociometer. In M. W. Baldwin (Ed.), Interpersonal cognition. (pp. 85-102). New York, NY: Guilford Press.

Leary, M. R., Haupt, A., Strausser, K., \& Chokel, J. (1998). Calibrating the sociometer: The relationship between interpersonal appraisals and state self-esteem. Journal of Personality and Social Psychology, 74, 1290-1299.

Lind, E. A., \& Tyler, T. R. (1988). The social psychology of procedural justice. New York, NY, US: Plenum Press.

Lodewijkx, H. F. M., Kersten, G. L. E., \& van Zomeren, M. (2008). Dual pathways to engage in 'silent marches' against violence: Moral outrage, moral cleansing and modes of identification. Journal of Community \& Applied Social Psychology, 18, 153-167.

McNall, L. A., Nicklin, J. M., \& Masuda, A. D. (2010). A meta-analytic review of the consequences associated with work-family enrichment. Journal of Business and Psychology, 25, 381-396.

Organ, D. W. (1988). Organizational citizenship behavior: The good soldier syndrome. Lexington, MA: Lexington Books.

Pennebaker, J. W., Francis, M. E., \& Booth, R. J. (2001). Linguistic Inquiry and Word Count: LIWC2001 [Computer software and manual]. Mahwah, NJ: Lawrence Erlbaum. 
Podsakoff, P. M., MacKenzie, S. B., Moorman, R. H., \& Fetter, R. (1990). Transformational leader behaviors and their effects on followers' trust in leader, satisfaction, and organizational citizenship behaviors. Leadership Quarterly, l, 107-142.

Podsakoff, N. P., Whiting, S. W., Podsakoff, P. M., \& Blume, B. D. (2009). Individual- and organizational-level consequences of organizational citizenship behaviors: A meta-analysis. Journal of Applied Psychology, 94, 122-141.

Routledge, C., Arndt, J., Sedikides, C., \& Wildschut, T. (2008). A blast from the past: The terror management function of nostalgia. Journal of Experimental Social Psychology, 44, 132-140.

Routledge, C., Arndt, J., Wildschut, T., Sedikides, C. M., Hart. C., Juhl, J., Vingerhoets, A. J. J. M., \& Schlotz, W. (2011). The past makes the present meaningful: Nostalgia as an existential resource. Journal of Personality and Social Psychology, 101, 638-652.

Routledge, C., Wildschut, T., Sedikides, C., \& Juhl, J. (2013). Nostalgia as a resource for psychological health and well-being. Social and Personality Psychology Compass, 7/11, 808818.

Routledge, C., Wildschut, T., Sedikides, C., Juhl, J., \& Arndt, J. (2012). The power of the past: Nostalgia as a meaning-making resource. Memory, 20, 452-460.

Sedikides, C., Hart, C., M., \& De Cremer, D. (2008). The self in procedural fairness. Social and Personality Psychology Compass, 2, 2107-2124.

Sedikides, C., Wildschut, T., Arndt, J., \& Routledge, C. (2006). Affect and the self. In J. P. Forgas (Ed.), Affect in social thinking and behavior: Frontiers in social psychology (pp. 197-215). New York, NY: Psychology Press

Sedikides, C., Wildschut, T., \& Baden, D. (2004). Nostalgia: conceptual issues and existential functions. In J. Greenberg, S. Koole \& T. Pyszczynski (Eds.), Handbook of experimental existential psychology (pp. 200-214). New York, NY: Guilford Press.

Sedikides, C., Wildschut, T., Routledge, C., \& Arndt, J. (in press). Nostalgia counteracts selfdiscontinuity and restores self-continuity. European Journal of Social Psychology.Sedikides, C., Wildschut, T., Routledge, C., Arndt, J., Hepper, E. G., \& Zhou, X. (2015). To nostalgize: Mixing memory with affect and desire. Advances in Experimental Social Psychology, 51. 
Sedikides, C., Wildschut, T., Routledge, C., Arndt, J., \& Zhou, X. (2009). Buffering acculturative stress and facilitating cultural adaptation: Nostalgia as a psychological resource. In R. S. Wyer, C. Y. Chiu, \& Y. Y. Hong (Eds.), Understanding culture: Theory, research and application (pp. 351-368). New York, NY: Psychology Press.

Seehusen, J., Cordaro, F., Wildschut, T., Sedikides, C., Routledge, C., Blackhart, G. C., Epstude, K., \& Vingerhoets, A. J. J. M. (2013). Individual differences in nostalgia proneness: The integrating role of the need to belong. Personality and Individual Differences, 55, 904-908.

Shore, L. M., Tetrick, L. E., Lynch, P., \& Barksdale, K. (2006). Social and economic exchange: construct development and validation. Journal of Applied Social Psychology, 36, 837-867.

Smith, H. J., Tyler, T. R., Huo, Y. J., Ortiz, J., \& Lind, E. A. (1998). The self-relevant implications of the group-value model: Group membership, self-worth, and treatment quality. Journal of Experimental Social Psychology, 34, 470-493.

Stephan, E., Sedikides, C., \& Wildschut, T. (2012). Mental travel into the past: Differentiating recollections of nostalgic, ordinary, and positive events. European Journal of Social Psychology, 42, 290-298.

Stephan, E., Wildschut, T., Sedikides, C., Zhou, X., He, W., Routledge, C., Cheung, W. Y., \& Vingerhoets, A. J. J. M. (2014). The mnemonic mover: Nostalgia regulates avoidance and approach motivation. Emotion, 14, 545-561.

Thau, S., Aquino, K., \& Poortvliet, P. M. (2007). Self-defeating behaviors in organizations: The relationship between thwarted belonging and interpersonal work behaviors. Journal of Applied Psychology, 92, 840 - 847.

Thibaut, J., \& Walker, L. (1975). Procedural justice: A psychological analysis. Hillsdale, NJ: Erlbaum.

Turner, R. N., Wildschut, T., \& Sedikides, C. (2012). Dropping the weight stigma: Nostalgia improves attitudes toward persons who are overweight. Journal of Experimental Social Psychology, 48, 130-137.

Turner, R., Wildschut, T., Sedikides, C., \& Gheorghiu, M. (2013). Combating the mental health stigma with nostalgia. European Journal of Social Psychology, 43, 413-422. 
Twenge, J. M., Zhang, L., Catanese, K. R., Dolan-Pascoe, B., Lyche, L. F., \& Baumeister, R. F. (2007), Replenishing connectedness: Reminders of social activity reduce aggression after social exclusion. British Journal of Social Psychology, 46, 205-224.

Tyler T. R., \& Blader, S. L. (2003). The Group Engagement Model: Procedural justice, social identity, and cooperative behavior. Personality and Social Psychology Review, 7, 349-61.

Tyler, T. R., \& Lind, E. A. (1992). A relational model of authority in groups. Advances in Experimental Social Psychology, 25, 115-191.

Tyler, T. R., \& Smith, H. J. (1999). Justice, social identity, and group processes. In T. R. Tyler, R. M. Kramer, \& O. P. John (Eds.), The psychology of the social self (pp. 223-264). Mahwah, NJ: Erlbaum.

Van den Bos, K. (1999). What are we talking about when we talk about no-voice procedures? On the psychology of the fair outcome effect. Journal of Experimental Social Psychology, 35, $560-577$.

Van den Bos, K., Vermunt, R., \& Wilke, H. A. M. (1996). The consistency rule and the voice effect: The influence of expectations on procedural fairness judgments and performance. European Journal of Social Psychology, 26, 411-428.

Van Dijke, M. H., \& De Cremer, D. (2008). How leader prototypicality affects followers' status: The role of procedural fairness. European Journal of Work and Organizational Psychology, 17, 226-250.

Van Dijke, M. H., De Cremer, D., Brebels, L., \& Van Quaquebeke, N. (in press). Willing and able: Action-state orientation and the relation between procedural justice and cooperation. Journal of Management.

Van Dijke, M. H., De Cremer, D., Mayer, D. A., \& Van Quaquebeke, N. (2012). When does procedural fairness promote organizational citizenship behavior? Integrating empowering leadership types in relational justice models. Organizational Behavior and Human Decision Processes, 117, 235-248.

Van Prooijen, J. -W. (2009). Procedural justice as autonomy regulation. Journal of Personality and Social Psychology, 96, 1166-1180. 
Van Prooijen, J. -W., Van den Bos, K., \& Wilke, H. A. M. (2002). Procedural justice and status: Status salience as antecedent of procedural fairness effects. Journal of Personality and Social Psychology, 83, 1353-1361.

Van Tilburg, W. A. P., Igou, E. R., \& Sedikides, C. (2013). In search of meaningfulness: Nostalgia as an antidote to boredom. Emotion, 13, 450-461.

Vess, M., Arndt, J., Routledge, C., Sedikides, C., \& Wildschut, T. (2012). Nostalgia as a resource for the self. Self and Identity, 11, 273-284.

Watson, D., Clark, L. A., \& Tellegen, A. (1988). Development and validation of brief measures of positive and negative affect: The PANAS scales. Journal of Personality and Social Psychology, 54, 1063-1070.

Wildschut, T., Sedikides, C., Arndt, J., \& Routledge, C. (2006). Nostalgia: content, triggers, functions. Journal of Personality and Social Psychology, 91, 975-993.

Wildschut, T., Sedikides, C., Routledge, C., Arndt, J., \& Cordaro, F. (2010). Nostalgia as a repository of social connectedness: The role of attachment-related avoidance. Journal of Personality and Social Psychology, 98, 573-586.

Williams, K. D., Forgas, J. P., \& von Hippel, W. (Eds.). (2005). The social outcast: Ostracism, social exclusion, rejection, and bullying. New York, NY: Psychology Press.

Williams, L. J., \& Anderson, S. E. (1991). Job satisfaction and organizational commitment as predictors of organizational citizenship and in-role behaviors. Journal of Management, 17, $601-617$.

Zhou, X., Sedikides, C., Wildschut, C., \& Gao, D.-G. (2008). Counteracting loneliness: On the restorative function of nostalgia. Psychological Science, 19, 1023-1029.

Zhou, X, Wildschut, T., Sedikides, C., Shi, K., \& Feng, C. (2012). Nostalgia: The gift that keeps on giving. Journal of Consumer Research, 39, 39-50.

Zhou, X., Wildschut, T., Sedikides, C., Chen, X., \& Vingerhoets, A. (2012). Heartwarming memories: Nostalgia maintains physiological comfort. Emotion, 12, 678-684. 


\section{Footnotes}

${ }^{1}$ Although there is little empirical evidence that cooperative responses to procedural justice are targeted at the source of justice (Colquitt et al., 2013), we tested whether nostalgia buffers the relation of procedural justice with specifically targeted OCB dimensions. The Podsakoff et al. (1990) instrument measures all dimensions of Organ's (1988) OCB taxonomy (altruism, conscientiousness, sportsmanship, courtesy, and civic virtue), but some of these dimensions overlap with each other in terms of target. OCB directed toward individuals (OCBI; altruism and courtesy) does not overlap with OCB directed toward the organization (OCBO; sportsmanship, civic virtue, and conscientiousness; Williams \& Anderson, 1991). The Nostalgia Proneness $\times$ Procedural Justice interaction significantly predicted OCBI, $\beta=-.22, t(126)=-2.57, p=.01$, $f^{2}=.03$, but not OCBO, $\beta=-.12, t(126)=-1.40, p=.17, f^{2}=.02$. A repeated measures ANOVA showed, however, that the Nostalgia Proneness $\times$ Procedural Justice interaction did not predict OCBI significantly more strongly than $\mathrm{OCBO}, F(1,126)=1.50, p=.22, \eta_{p}^{2}=.01$.

${ }^{2}$ A trained coder, who was unaware of the study hypotheses and procedure, coded all narratives. We used the coding scheme developed by Wildschut et al. (2006), and extended this to also code events in terms of work experiences and interactions with authorities. In terms of primary involved actors, 35 nostalgic narratives and 50 control narratives could be classified. Fewer nostalgic (14\%) than control narratives (28\%) involved only the self, few nostalgic (3\%) and control narratives (2\%) involved a stranger, about half of nostalgic (46\%) and control narratives (50\%) involved friends, more nostalgic (37\%) than control narratives $(10 \%)$ involved parents, partners, or brothers/sisters, no nostalgic and some control narratives (8\%) involved a colleague or supervisor. Relative to prominence of the self, close family members were significantly more prominent in nostalgic than control narratives, $\chi^{2}(1)=8.02$, $p=.01$. Narratives were also coded for expressions of relational appreciation. Companionship was expressed in more nostalgic $(64 \%)$ than control narratives $(36 \%), \chi^{2}(1)=5.13, p=.02$. Further, more nostalgic (47\%) than control narratives (26\%) expressed being liked, accepted, or trusted by others, $\chi^{2}(1)=4.34, p=.04$, and more nostalgic $(60 \%)$ than control narratives (38\%) expressed liking, accepting, or trusting others, $\chi^{2}(1)=4.83, p=.03$. 
Coding narratives from undergraduate students may not shed light on the relevance of work experiences or interactions with authorities to nostalgic experiences of employees. In a pilot study, we therefore recruited via Amazon's Mechanical Turk 76 employees who had a supervisor (45 men, 31 women; $M_{\mathrm{age}}=32.46, S D_{\mathrm{age}}=9.77 ; \$ 1.00$ payment). We instructed half of them to recall an organizational episode of low procedural justice. The other half did not recall an organizational event. Next, we instructed all participants to recall and then write about a nostalgic event from their past (Wildschut et al., 2006). Content coding of these nostalgic narratives revealed that work experiences played a very minor role. In contrast with the central role of friends (30\%), and partners, parents, and brothers/sisters (44\%), colleagues and supervisors figured in only $3 \%$ of nostalgic recollections, regardless of whether participants first recalled an instance of organizational adversity (i.e., low justice) or not. Yet, in line with previous research (Abeyta et al., in press; Wildschut et al., 2006), themes of connectedness and companionship (albeit not with colleagues or supervisors) were prominent. These results support the notion of nostalgia as a repository of social connectedness.

${ }^{3}$ When nostalgia proneness was $1 S D$ below the mean, there was a significant indirect effect of procedural justice on cooperation via social connectedness, $a b=3.50,95 \% \mathrm{CI}: 1.32$, 5.98. When nostalgia proneness was $1 S D$ above the mean, the indirect effect of procedural justice on cooperation via social connectedness was not significant, $a b=.74,95 \%$ CI: -.97 , 2.34 .

${ }^{4}$ Power analysis revealed that, assuming a medium effect size, $p<.05$, and power $=.80$ (Cohen, 1988), $N$ required to detect the Procedural Justice x Nostalgia interaction effect on cooperation was 130 . Overall, our studies were thus adequately powered to detect a medium sized effect. 
Table 1

Correlations Between Variables in Study 1

\begin{tabular}{|c|c|c|c|c|c|c|c|}
\hline \multirow[b]{2}{*}{ Variable } & \multicolumn{7}{|c|}{ Correlation with } \\
\hline & 1 & 2 & 3 & 4 & 5 & 6 & 7 \\
\hline 1. Gender & -- & & & & & & \\
\hline 2. Age & .12 & -- & & & & & \\
\hline 3. Education level & -.03 & -.09 & -- & & & & \\
\hline 4. Organization tenure & .14 & $.57 * * *$ & -.03 & -- & & & \\
\hline 5. Procedural justice & -.02 & -.01 & .05 & .16 & -- & & \\
\hline 6. Nostalgia proneness & .15 & -.03 & .09 & .15 & $.26^{* *}$ & -- & \\
\hline 7. OCB & .08 & $.20 *$ & $-.26 *$ & $.25 * *$ & .11 & .14 & -- \\
\hline
\end{tabular}

Note. $N=130 ;$ Gender was coded: $1=$ male, $2=$ female

$* p<.05 ; * * p<.01 ; * * * p<.001$. 


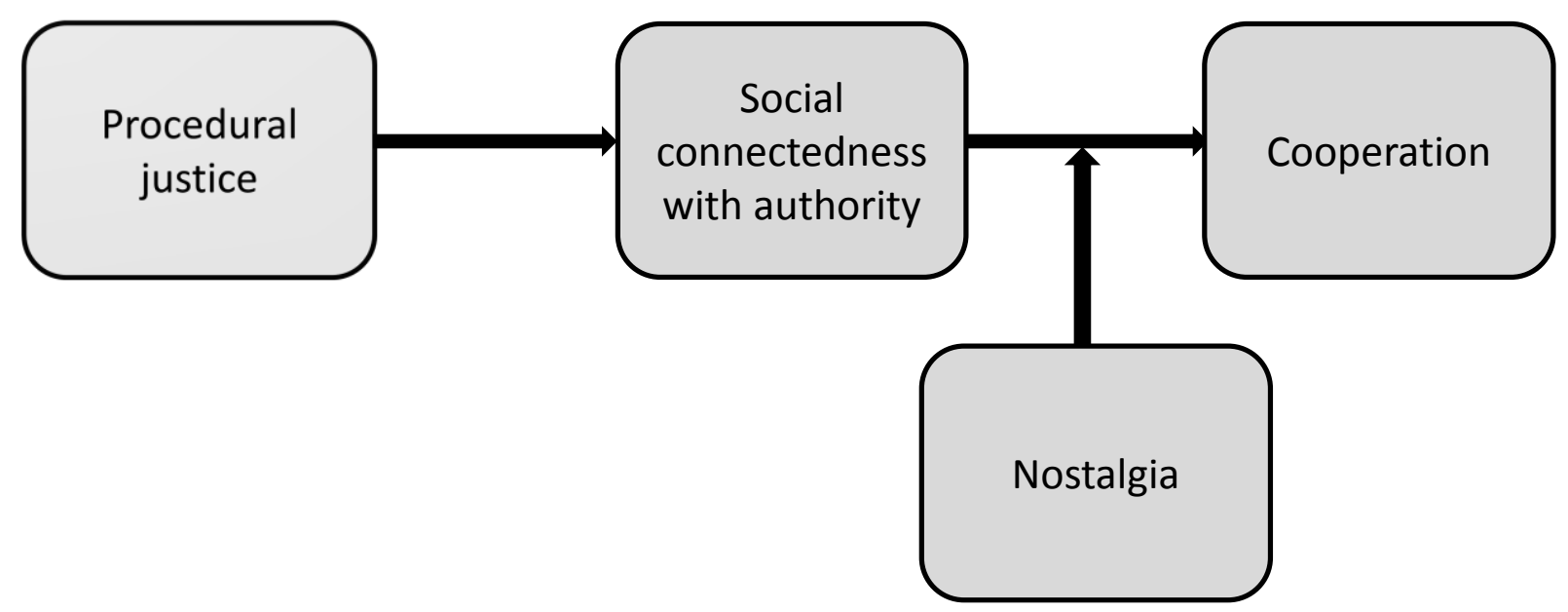

Figure 1. How Nostalgia Buffers the Effect of Low (vs. High) Procedural Justice on Cooperation. 


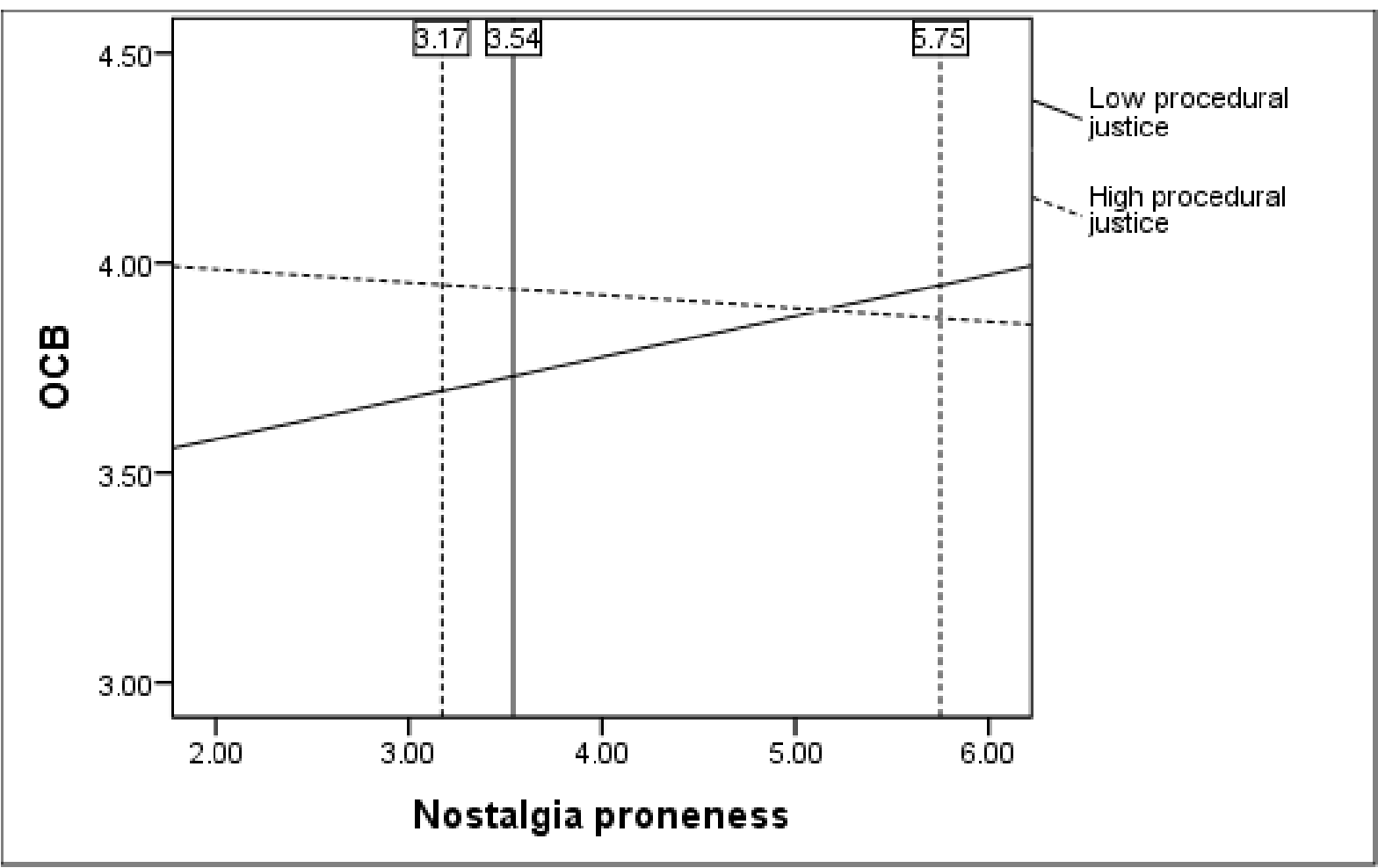

Figure 2. The relation between procedural justice and employee OCB as a function of nostalgia proneness in Study 1. For nostalgia proneness scores below 3.54 (.71 SD below the mean; represented by the solid vertical line) low (compared to high) procedural justice was significantly $(p<.05)$ associated with decreased OCB. For nostalgia proneness scores above 3.54 , the relation between procedural justice and OCB was not significant. The dashed vertical lines represent the simple slopes of the relation between procedural justice at $1 S D$ below and above the mean of nostalgia proneness, respectively. 


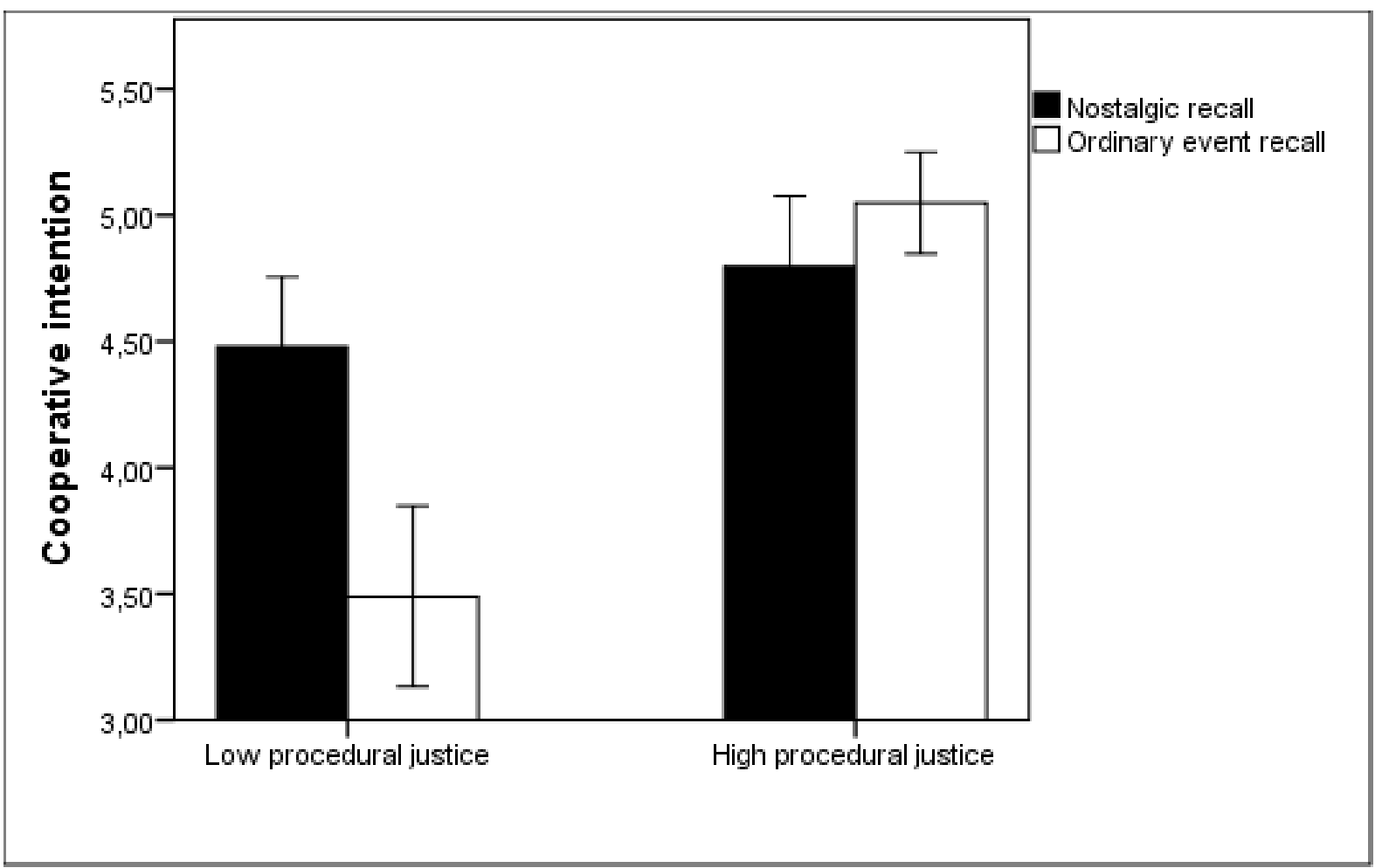

Figure 3. The effect of procedural justice on cooperative intentions as a function of nostalgia in Study 2. 


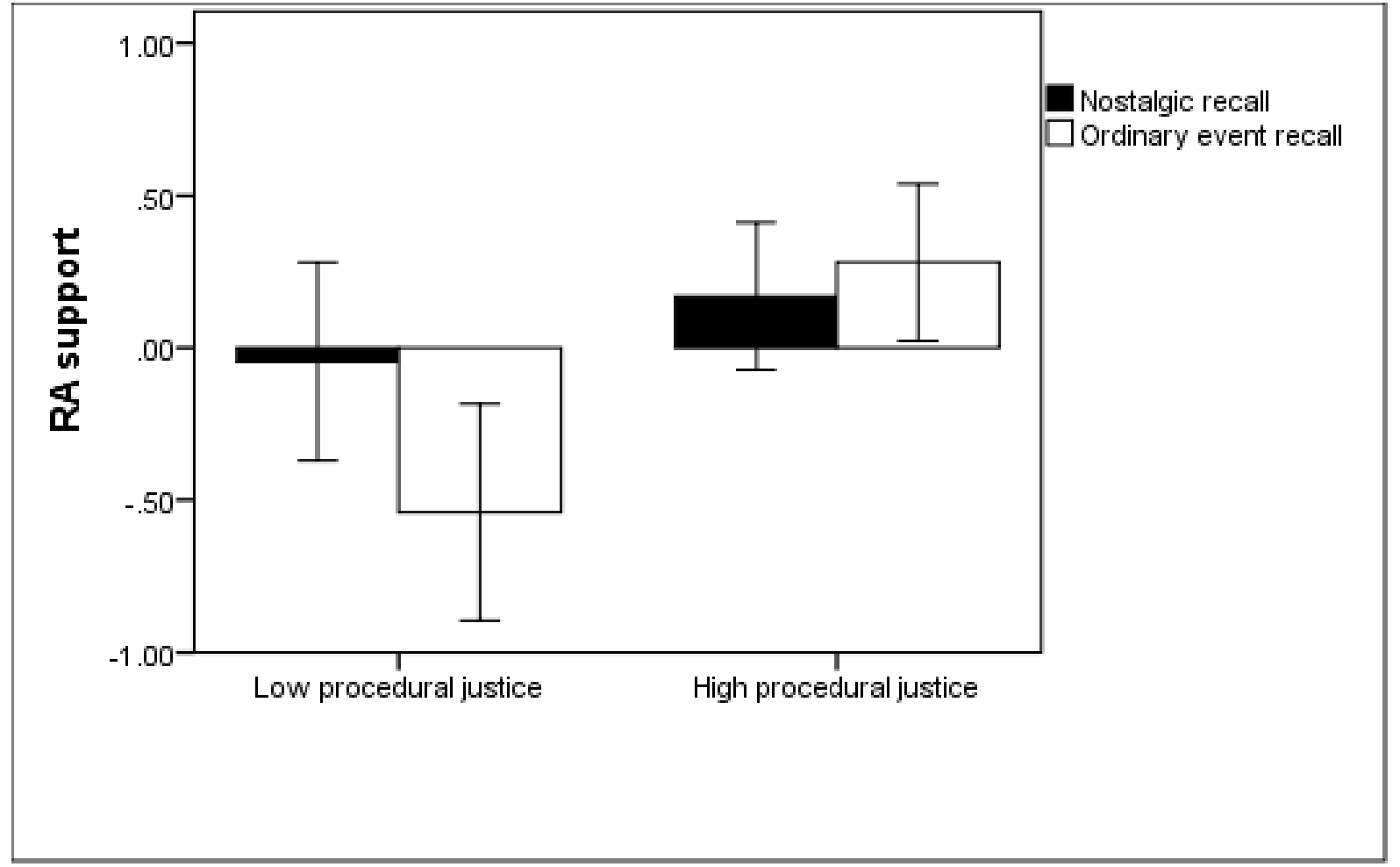

Figure 4. The effect of procedural justice on support for RA as a function of nostalgia in Study 3. 


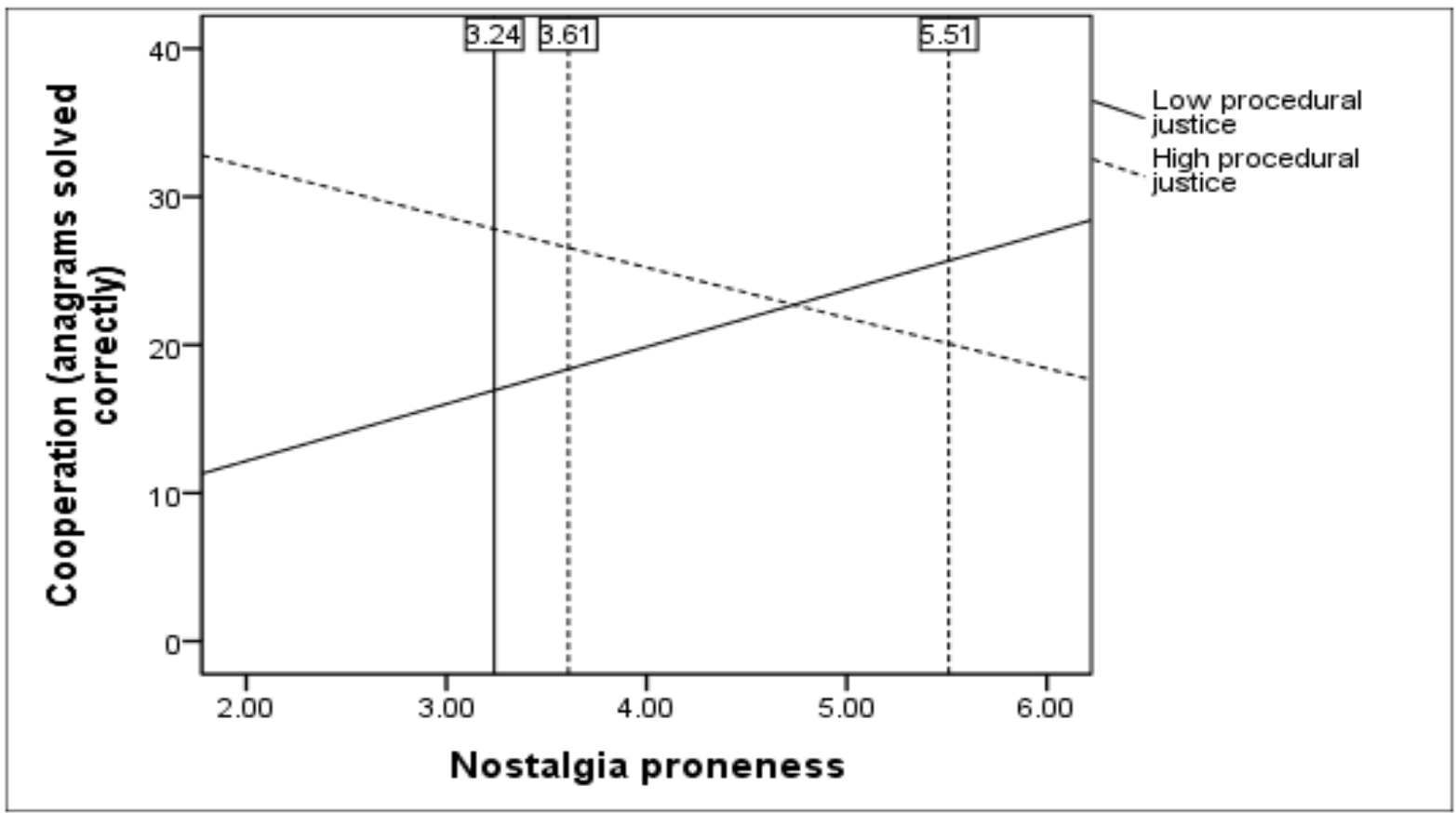

Figure 5. The effect of procedural justice on cooperation (number of anagrams solved correctly) as a function of nostalgia proneness in Study 4. For nostalgia proneness scores below 3.24 (1.39 SD below the mean), low (compared to high) procedural justice significantly ( $p<$ .05) decreased cooperation. For nostalgia proneness scores above 3.24, the effect of procedural justice on cooperation was not significant. The dashed vertical lines represent the simple slopes of the effect of procedural justice on cooperation at $1 S D$ below and above the mean of nostalgia proneness, respectively. 


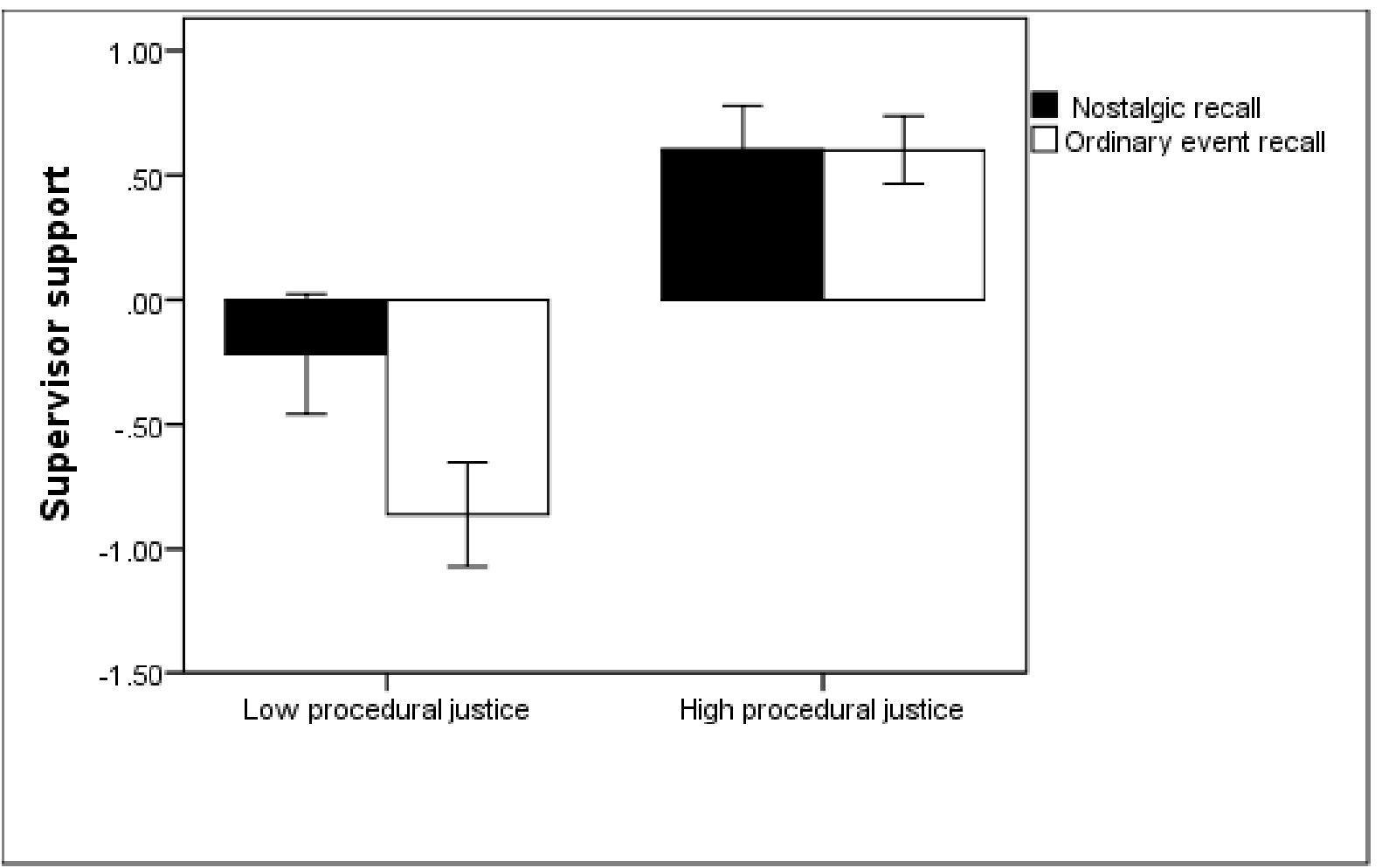

Figure 6. The effect of procedural justice on support for the supervisor as a function of nostalgia in Study 5 . 